\title{
The preparation and properties of 1,1-difluorocyclopropane derivatives
}

\author{
Kymbat S. Adekenova ${ }^{1}$, Peter B. Wyatt ${ }^{1}$ and Sergazy M. Adekenov ${ }^{* 2}$
}

Review

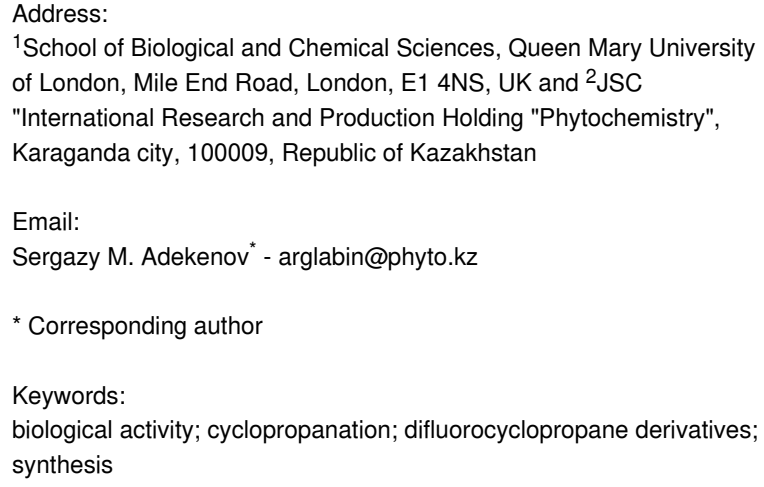

${ }^{1}$ School of Biological and Chemical Sciences, Queen Mary University of London, Mile End Road, London, E1 4NS, UK and 2JSC

"International Research and Production Holding "Phytochemistry", Karaganda city, 100009, Republic of Kazakhstan

Email:

Sergazy M. Adekenov* - arglabin@phyto.kz

* Corresponding author

Keywords:

biological activity; cyclopropanation; difluorocyclopropane derivatives; synthesis

\author{
Beilstein J. Org. Chem. 2021, 17, 245-272. \\ https://doi.org/10.3762/bjoc.17.25 \\ Received: 21 July 2020 \\ Accepted: 07 December 2020 \\ Published: 26 January 2021 \\ Associate Editor: D. Y.-K. Chen \\ (C) 2021 Adekenova et al.; licensee Beilstein-Institut. \\ License and terms: see end of document.
}

\begin{abstract}
Recently, the functionalization of organic molecules with fluorine substituents has grown rapidly due to its applications in such fields as medicine, agriculture or materials sciences. The aim of this article is to review the importance of 1,1-difluorocyclopropane derivatives in synthesis. It will examine the role of the fluorine substituents in both ring-forming and ring-opening reactions, as well as methods for obtaining difluorocyclopropanes as single enantiomers. Several examples are provided to highlight the biological importance of this class of compounds.
\end{abstract}

\section{Introduction}

The chemistry of cyclopropane derivatives is one of the most intensively developing fields of organic chemistry. In the past decade there have been made many investigations to develop new chemo-, regio- and stereoselective methods for the synthesis and transformations of cyclopropane derivatives. These investigations gained a significant interest, because cyclopropane and cyclopropene fragments are present in the structures of many biologically active substances, such as antibiotics, anticancer, and antimycotic preparations, controllers of plant growth and fruit ripening, and insecticides. Geminal dihalocyclopropanes, especially the fluoro derivatives, form an important class of organic compounds, which have the ability to participate in synthetically useful reactions due to the presence of both, ring strain and of the gem-dihalomethylene fragment. Thus, they are of interest not only for the direct application as biologically active substances and functional materials but also as precursors to other fluorine-containing compounds [1,2]. Fluorine forms stable bonds to carbon and due to its high electronegativity it can profoundly modify the physicochemical properties of the parent molecules. In biologically active materials fluorine substituents can affect the charge distribution, electrostatic surface, and solubility of chemical entities, thus often leading to useful outcomes. Incorporating a fluorine group into natural compounds has been widely accepted as a powerful tool 
for discovering new drugs and agrochemicals. The number of medicinal preparations containing at least one fluorine atom in the structure is now very high [3-5].

In this review we give an overview of the chemistry of 1,1difluorocyclopropanes. First, we discuss the synthetic routes to gem-fluorocyclopropane derivatives. Then, we review the chemical transformations, emphasizing ring-opening reactions. Finally, we survey the biological activity of significant molecules that possess the 1,1-difluorocyclopropane fragment in the structure. A number of previous reviews dealing with the synthesis and applications of difluorocyclopropanes are available [2,6-8]. Here we will focus on selected synthetically and biologically useful examples.

\section{Review}

\section{Synthesis of 1,1-difluorocyclopropanes}

An early work on the synthesis and reactivity of fluorinated cyclopropanes was described by Atkinson in 1952 [9], followed by Tarrant [10], and Misani [11]. Tarrant, Lovelace and Lilyquist synthesized 1,1-difluoro-2,3-dimethylcyclopropane (2) by a reductive debromination using zinc metal (Scheme 1) [10].<smiles>CC(Br)C(C)C(F)(F)Br</smiles>

1

$$
\underset{\substack{\text { 1-propanol } \\ \text { reflux }}}{\stackrel{\mathrm{Zn}, \mathrm{ZnCl}_{2}}{\longrightarrow}}
$$

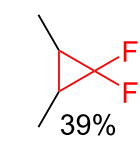

2
Scheme 1: Synthesis of 1,1-difluoro-2,3-dimethylcyclopropane (2)

After 1960 further methods of generating difluorocarbenes became available. These methods contributed to the synthesis of a wide variety of fluorinated cyclopropanes. In 2003, two reviews by Dolbier [7] and Fedorynski [8] were published on the methods of synthesis and use of difluorocyclopropanes in organic synthesis. They discussed in detail the various approaches for the synthesis of difluorocyclopropanes, so in this review we will supplement this information by methods for the synthesis of difluorocyclopropanes, paying particular attention to the practical methods of synthesis and transformation.

Three main approaches to the preparation of difluorocyclopropane and its derivatives can be distinguished: carbene and non-carbene methods of cyclopropanation along with functional group transformations of existing cyclopropanes.

The most popular route to prepare fluorocyclopropanes is to generate fluorine-containing carbenes (or carbenoids), which then react with multiple bonds, resulting in cyclopropanation.
One of the important properties of fluorine-containing carbenes and carbenoids is their electrophilicity, which is a result of the high electronegativity of fluorine. Also, fluorine has an $+M$ effect which tends to reduce the reactivity of the carbenes. The carbene-based methods typically give the highest yields when alkenes with electron-donating substituents are used. There are few examples in which the cyclopropanation by carbene methods of electron-deficient alkenes containing substituents with a large $-\mathrm{M}$ effect (for example, $\mathrm{CO}_{2} \mathrm{R}, \mathrm{COR}, \mathrm{CN}, \mathrm{SO}_{2} \mathrm{R}$ ) were successful. Therefore, alternative methods such as intramolecular cyclizations, exchange fluorination, and transformation of functional groups in fluorinated rings have been developed in order to provide access to fluorinated cyclopropanes with electron-withdrawing substituents.

\subsection{Difluorocarbene methods with non-metal sources}

Difluorocarbene chemistry was first reported by Doering in 1954 [12]. The lone electron pairs on the fluorine substituents interact with the carbene center, making the structure stabilized [13]. Difluorocyclopropanes 4 were synthesized from the reaction of halodifluoromethanes and alkenes (Scheme 2). The elimination of hydrogen halide from the halodifluoromethane under basic conditions (metal alkoxide or alkyllithium) generated difluorocarbene $[14,15]$. The low yields of the product have been attributed to the facile addition of the strong bases to difluorocarbene. The yields were best in the reactions with electron-rich alkenes and when a low concentration of the base was used to minimize the destruction of difluorocarbene. The use of oxirane or epichlorohydrin as hydrogen halide scavengers avoided the need for a stoichiometric amount of the strong base $[16,17]$. The opening of the oxirane ring by bromide ions under homogeneous conditions generated a bromoalkoxide ion which then acted as the base, leading to cyclopropanes $\mathbf{4}$ and $\mathbf{6}$ (Scheme 2). However, the harsh conditions needed (high temperatures, autoclave) limited the approach.

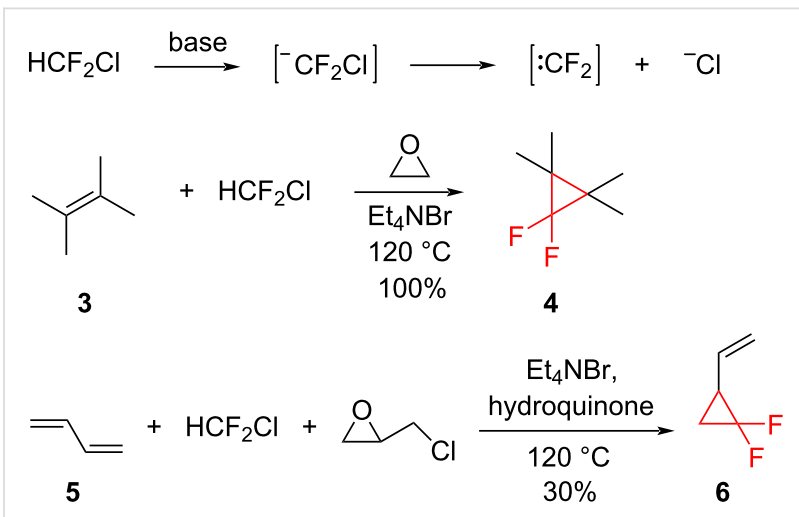

Scheme 2: Cyclopropanation via dehydrohalogenation of chlorodifluoromethane. 
In the case of electron-rich alkenes dibromodifluoromethane is a suitable source of difluorocarbene. However, the same reagent produces low yields in the reactions with electron-deficient alkenes. Dolbier et al. reported the cyclopropanation of $\alpha$-methylstyrene (7) using dibromodifluoromethane and zinc dust in the presence of iodine (Scheme 3) [18].

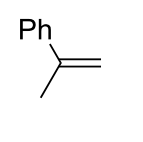

7

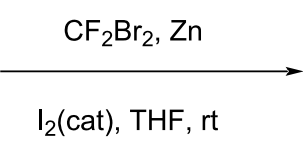

$\mathrm{I}_{2}$ (cat), THF, rt

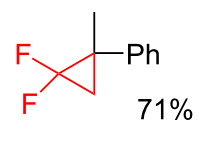

8
Scheme 3: Difluorocyclopropanation of methylstyrene 7 using dibromodifluoromethane and zinc.

The reduction of dibromodifluoromethane was also used for the approach of Burton and Naae (Scheme 4), which is again suitable for electron-rich alkenes [19]. Dibromodifluoromethane reacted with triphenylphosphine to give a phosphonium salt, which then decomposed to difluorocarbene. The yields from this method were increased when potassium fluoride and 18-crown-6 were added to the reaction mixture [20].<smiles>C1=COCCC1</smiles>

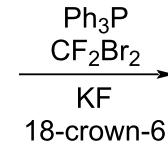
$25^{\circ} \mathrm{C}$<smiles>O=C(O)OC1C2CCCOC21</smiles>

10
Scheme 4: Synthesis of difluorocyclopropanes from the reaction of dibromodifluoromethane and triphenylphosphine.

Dehydrohalogenation of dichlorodifluoromethane under phase-transfer catalysis: Difluorocarbene can be generated from chlorodifluoromethane by phase-transfer catalysis (PTC) through the reaction with $\mathrm{NaOH}$ or $\mathrm{KOH}$, or a solid base, using a tetraalkylammonium salt as the catalyst. However, the resulting difluorocarbene is ineffective for the cyclopropanation of alkenes. This is because the intermediate chlorodifluoromethyl anion is very short-lived and does not move from the interfacial region to the bulk organic phase, making hydrolysis the dominant reaction pathway. However, the reaction of chlorodifluoromethane with concentrated $\mathrm{KOH}$ in dioxane in the presence of tetraphenylarsonium chloride as the catalyst, provided low yields $(<30 \%)$ of the cyclopropanation products [9]. Therefore, another modified method was developed, especially as this method was limited to nucleophilic alkenes.

It is possible to obtain difluorocarbene from the reaction of bromoform (or methylene bromide) with dibromodifluoromethane. Here, bromoform (or methylene bromide) is deprotonated, resulting in the formation of tribromo- or dibromomethyl carbanions. The so-obtained carbanions form lipophilic ion pairs with the catalyst cation and move into the organic phase, where they react with dibromodifluoromethane. Consequently, carbon tetrabromide (or bromoform) and the ion pair $\mathrm{CBrF}_{2}{ }^{-} \mathrm{N}^{+} \mathrm{Bu}_{4}$ are formed. The ion pair decomposes into TBAB and difluorocarbene, which then can react with alkenes producing the gem-difluorocyclopropane derivatives such as $\mathbf{4}$ (Scheme 5) [21].

Chlorodifluoromethane as a source of difluorocarbene in the reaction: The advantage of using of tetraarylarsonium salts as effective phase-transfer catalysts for the two-phase reaction of chlorodifluoromethane (freon 22, 11) with $\alpha$-methylstyrene (7) was demonstrated by Barbasiewicz [22] (Scheme 6). The reaction proceeded at room temperature for $4 \mathrm{~h}$ with the formation of the cyclopropane derivative $\mathbf{8}$.

Chloro- and bromodifluoroacetate salts as difluorocarbene sources: The sodium salt of chlorodifluoroacetic acid

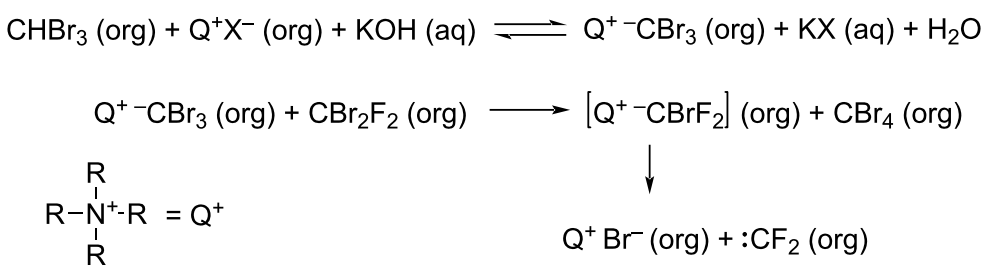

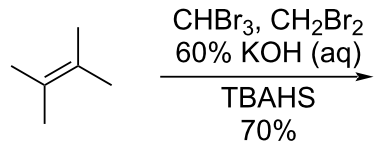

3

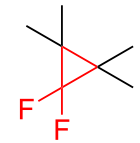

4 


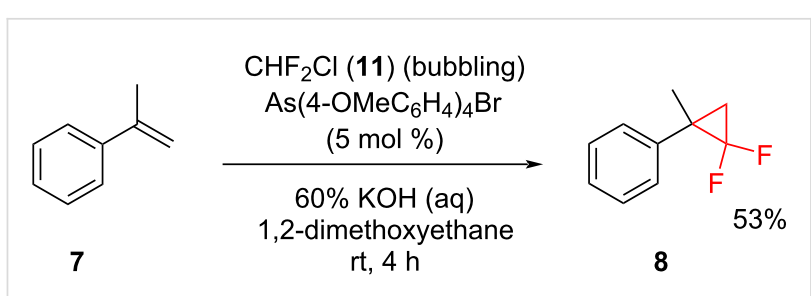

Scheme 6: The reaction of methylstyrene 7 with chlorodifluoromethane (11) in the presence of a tetraarylarsonium catalyst.

$\left(\mathrm{ClCF}_{2} \mathrm{COONa}, 12\right)$ is one of the most commonly used reagents for the difluorocyclopropanation. The first published method for the generation of gem-difluorocyclopropanes comprised the addition of sodium chlorodifluoroacetate (12) to the disubstituted alkene $\mathbf{1 3}$ in refluxing diglyme or triglyme at $190{ }^{\circ} \mathrm{C}$ (Scheme 7) [23].

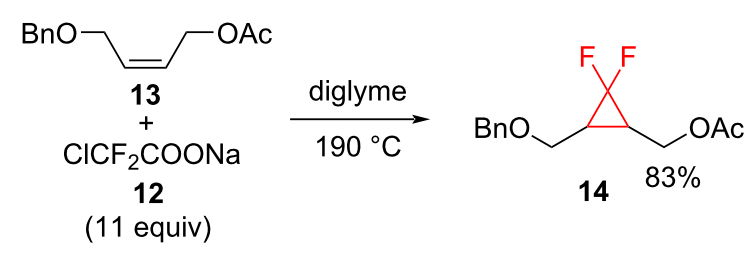

Scheme 7: Pyrolysis of sodium chlorodifluoroacetate (12) in refluxing diglyme in the presence of alkene 13.

The method has been widely used for the difluorocyclopropanation of allylic alcohol derivatives [24], steroids [25], and $\mathrm{N}$-Boc-protected enamides [26]. Boron-substituted difluorocyclopropanes $\mathbf{1 6}$ can be also obtained from 12. Fujioka and Amii [27] prepared the versatile building blocks $\mathbf{1 6}$ by the reaction of $\mathbf{1 2}$ with alkenyl boronates $\mathbf{1 5}$ (Scheme 8).

$$
\overbrace{\mathrm{R}^{1}}^{\mathrm{R}^{3} \mathrm{O}}
$$

15
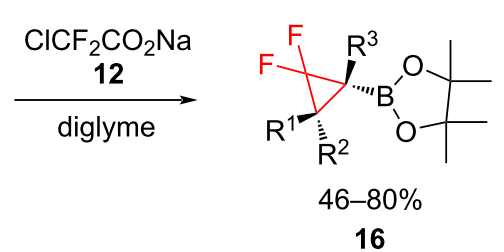

16

Scheme 8: Synthesis of boron-substituted gem-difluorocyclopropanes 16.

Although this method is one of the most popular and reliable ones, it does have some drawbacks, particularly the high temperatures that are required $\left(180-190{ }^{\circ} \mathrm{C}\right)$. Another disadvantage is the use of excess amounts of $\mathrm{ClCF}_{2} \mathrm{COONa}$ (12). Thus, the reaction of 2,2-difluorostyrenes and $\mathbf{1 2}$ in diglyme at $180{ }^{\circ} \mathrm{C}$ gave 1-aryl-2,2,3,3-tetrafluorocyclopropane as a primary product. After prolonged reaction under these conditions, 1,1,2,2- tetrafluoroindanes were the only products isolated [28]. In addition, it is hard to work with sodium chlorodifluoroacetate, as it is highly hygroscopic and deliquescent [29]. Hence, in order to avoid these issues, sodium bromodifluoroacetate (17) may be used (Scheme 9).

$$
\underset{R^{2}}{R_{R^{4}}^{R^{3}}} \stackrel{\mathrm{BrCF}_{2} \mathrm{CO}_{2} \mathrm{Na}}{\stackrel{17}{\text { diglyme, } 180{ }^{\circ} \mathrm{C}}}
$$

Scheme 9: Addition of sodium bromodifluoroacetate (17) to alkenes.

Amii and co-workers compared the efficiency of the two reagents, $\mathrm{ClCF}_{2} \mathrm{COONa}(\mathbf{1 2})$ and $\mathrm{BrCF}_{2} \mathrm{COONa}(17)$, in the difluorocyclopropanation of 1,1-diphenylethene (18) [29] and the results are summarized in Table 1 . They showed that it was easier and more efficient to work with sodium bromodifluoroacetate (17). The application of the same conditions resulted in almost $100 \%$ yield, when using $\mathbf{1 7}$. The major advantages of $\mathbf{1 7}$ over $\mathbf{1 2}$ are that the bromo derivative $\mathbf{1 7}$ is stable at room temperature and requires a lower temperature than $\mathbf{1 2}$ to decompose to difluorocarbene.

Table 1: Comparison of halodifluoroacetates 12 and 17 in the difluorocyclopropanation of 1,1-diphenylethene (18).

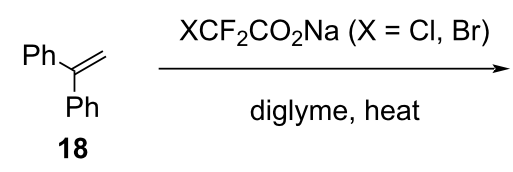

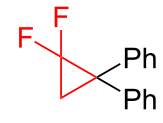

19

\begin{tabular}{llll}
\hline entry & $\mathrm{XCF}_{2} \mathrm{CO}_{2} \mathrm{Na}$ & conditions & yield 19 (\%) \\
\hline 1 & $\mathrm{ClCF}_{2} \mathrm{CO}_{2} \mathrm{Na}(12)$ & $180{ }^{\circ} \mathrm{C}, 20 \mathrm{~min}$ & 96 \\
2 & $\mathrm{ClCF}_{2} \mathrm{CO}_{2} \mathrm{Na}(12)$ & $150{ }^{\circ} \mathrm{C}, 20 \mathrm{~min}$ & 64 \\
3 & $\mathrm{BrCF}_{2} \mathrm{CO}_{2} \mathrm{Na}(17)$ & $150{ }^{\circ} \mathrm{C}, 20 \mathrm{~min}$ & 99 \\
4 & $\mathrm{BrCF}_{2} \mathrm{CO}_{2} \mathrm{Na}(17)$ & $120^{\circ} \mathrm{C}, 20 \mathrm{~min}$ & 76
\end{tabular}

By the use of $\mathrm{BrCF}_{2} \mathrm{COONa}$ in diglyme at $150{ }^{\circ} \mathrm{C}$, various alkyl- and aryl-substituted alkenes, allyl alcohol esters, $\alpha, \beta$ unsaturated esters, and alkenyl (pinacol) boranes 16 were transformed into the corresponding difluorocyclopropanes in 93-99\% yields. Highly sensitive substrates such as trimethylsilylenol ethers $\mathbf{2 0}$ can also be used in this method in order to prepare the difluorocyclopropanes 21 with good yields (Scheme 10) [29,30].

In addition, another modification was made in order to increase the speed of the reaction of sodium halodifluoroacetate and alkenes. This was achieved by the use of microwave irradiation 
<smiles>COC1=CCNCC1</smiles>

$20 a-c$

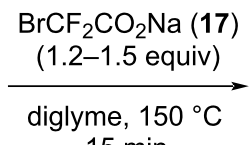

$15 \mathrm{~min}$

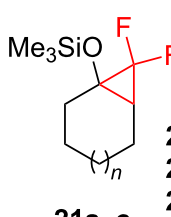

21a $n=1: 73 \%$

21b $n=2: 77 \%$

21a-c 21c $n=3: 73 \%$

Scheme 10: Addition of sodium bromodifluoroacetate (17) to silyloxysubstituted cyclopropanes 20.

in THF solution, which allowed the reactions to be completed within 5 minutes [31].

An application of this method to targets of biological interest was provided by Csuk and Eversmann [32] who performed the synthesis of difluorinated nucleosides (Scheme 11). The difluorocyclopropane derivative $\mathbf{1 4}$ was prepared using sodium chlorodifluoroacetate (12) as a source of the carbene (Scheme 11). The subsequent deacetylation of $\mathbf{1 4}$ resulted in the formation of alcohol $\mathbf{2 2}$, which was then reacted with nucleoside analogs via a Mitsunobu reaction to generate the racemic difluorinated carbocyclic homonucleoside analogs $\mathbf{2 3}$ and $\mathbf{2 4}$ in good yields.

(Triphenylphosphonio)difluoroacetate (PDFA, $\left.\mathrm{Ph}_{3} \mathrm{P}^{+} \mathrm{CF}_{2} \mathrm{CO}_{2}^{-}\right)$as a difluorocarbene source: PDFA is avail- able from the reaction of triphenylphosphine with halodifluoroacetate salts such as $\mathrm{BrCF}_{2} \mathrm{CO}_{2} \mathrm{~K}$. It exists as a free-flowing white solid that is not sensitive to air or moisture [33]. Upon heating to $80{ }^{\circ} \mathrm{C}$ in $\mathrm{N}$-methylpyrrolidone, the compound decarboxylates and acts as a source of the ylide $\mathrm{Ph}_{3} \mathrm{P}^{+} \mathrm{CF}_{2}{ }^{-}$, which was used for the Wittig olefination of aldehydes and ketones. However, heating PDFA in nonpolar solvents (e.g., xylene at $90^{\circ} \mathrm{C}$ ) favors the dissociation of the ylide to release difluorocarbene which is able to effect the cyclopropanation of alkenes [34].

Trimethylsilyl fluorosulfonyldifluoroacetate (TFDA) as a difluorocarbene source: Highly efficient methods for the difluorocyclopropanation of both electron-rich and electrondeficient alkenes using $\mathrm{FSO}_{2} \mathrm{CF}_{2} \mathrm{COOSiMe}_{3}$ (TFDA, 25) as a source of difluorocarbene were described by the Dolbier group in 2000 [13,35]. The difluorocarbene generated by this method was able to add at moderate temperatures to unreactive alkenes such as butyl acrylate (26) (Scheme 12). Fluoride ions can initiate a chain process, whereby TFDA undergoes desilylation which is followed by a subsequent decarboxylation, and loss of $\mathrm{SO}_{2}$ to form difluorocarbene $\mathrm{CF}_{2}$ and $\mathrm{F}^{-}$; $\mathrm{NaF}$ was found to be superior to both $\mathrm{CsF}$ and $\mathrm{KF}$ as an initiator.

Difluorocarbene generated from TFDA (25) also readily reacted with propargyl esters 27 at the triple bond (Scheme 13). The

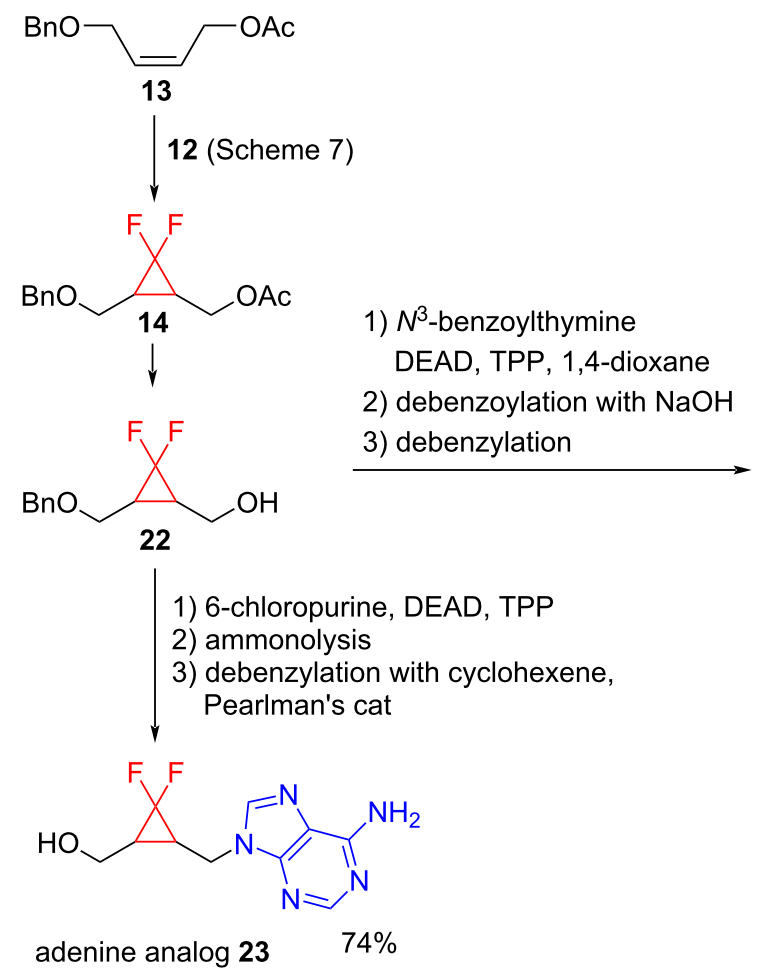

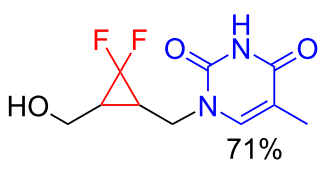

thymine analog 24 


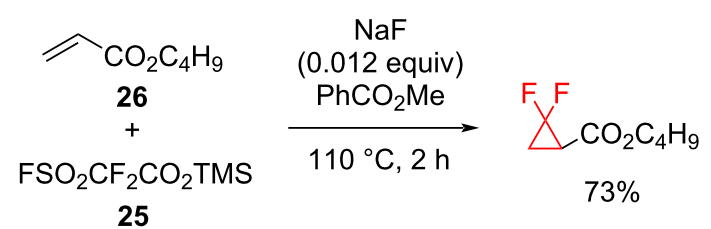

Scheme 12: Addition of butyl acrylate (26) to difluorocarbene generated from TFDA (25).

difluorocyclopropenes $\mathbf{2 8}$ were further converted into the difluorocyclopropyl ketones $\mathbf{2 9}$ by alkaline hydrolysis and isomerization [36].

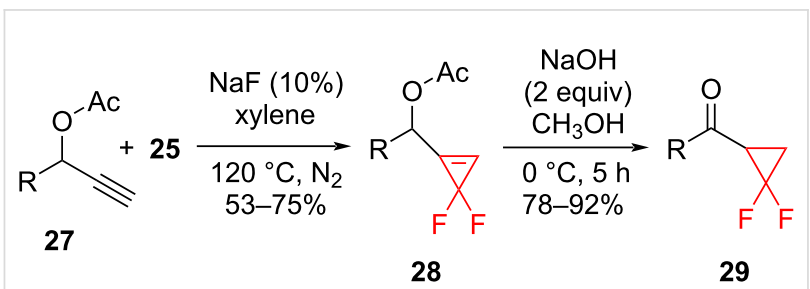

$\mathrm{R}=$ aryl, alkyl, $\mathrm{H}$

Scheme 13: Addition of difluorocarbene to propargyl esters 27 and conversion of the difluorocyclopropenes $\mathbf{2 8}$ to difluorocyclopropyl ketones 29.

Several nitrogen nucleophiles have been evaluated as catalysts to promote the difluorocarbene formation from TFDA in order to bring about the cyclopropanation of a 2-siloxybuta-1,3-diene derivative; 1,8-bis(dimethylamino)naphthalene (proton sponge) was found to be particularly effective [37].

Methyl 2,2-difluorosulfonyldifluoroacetate as a source of difluorocarbene: Eusterwiemann et al. devised a method for the generation of difluorocyclopropanes using methyl 2,2difluoro-2-(fluorosulfonyl)acetate (MDFA, 30) as a source of difluorocarbene (Scheme 14) [38]. The difluorocyclopropanation of $\alpha$-methylstyrene (7) by MDFA gave the corresponding difluorocyclopropane $\mathbf{8}$ in $82 \%$ NMR yield.

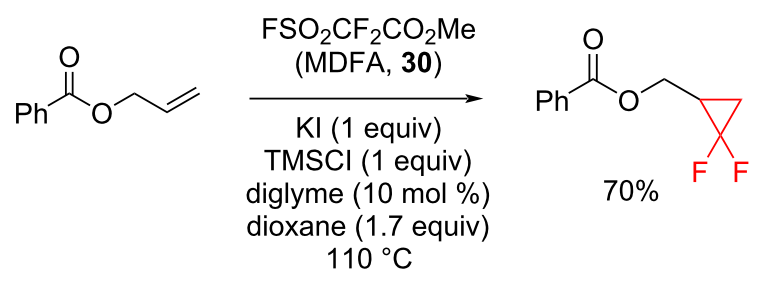

Scheme 14: The generation of difluorocyclopropanes using MDFA 30.
The conditions used with MDFA were similar to those for TFDA. Minimal amounts of solvent were applied, keeping the concentrations high. The fluoride trap TMSCl which is both corrosive and volatile, could be replaced by hexamethyldisiloxane (HMDSO), however, then, the reaction required a longer time to complete. When HMDSO was used in the cyclopropanation of 7 the yield of 8 was decreased to $73 \%$ [38]. TFDA (25) and MDFA (30) have comparable reactivity; however, $\mathbf{3 0}$ is a better choice of difluorocarbene source in terms of safety, cost, preparation, and ease of storage.

The generation of difluorocarbene from trimethyl(trifluoromethyl)silane: One more modified method, which also increases the rate of the reaction, is the generation of difluorocarbene from $\mathrm{TMSCF}_{3}(\mathbf{3 1})$, which is also known as the Ruppert-Prakash reagent [39]. The advantages of this reagent are its safety, low cost, and commercial availability. The reagent is compatible with a range of functionalized substrates for the gem-difluorocyclopropanation when using $\mathrm{NaI}$ as an initiator (Table 2). Both, electron-rich and comparatively electronpoor examples have been described. Flow reaction conditions were also applied to this reaction (Scheme 15). The reagents were premixed in THF at room temperature and injected into a heated reactor fitted with a back pressure regulator to allow operation at temperatures that exceeded the boiling point of the solvent. In this flow chemistry setup there was an opportunity to control the temperature, pressure, and to make the heat transfer more efficient [40]. The separate injection of a solution of the carbene precursor and of the alkene premixed with the activator did not lead to any improvement. Rullière et al. also tested this method on simple alkenes, electron-rich styrenes, and styrenes with electron-withdrawing substituents in the structure [40]. The yields of the gem-difluorocyclopropanes from the styrene derivatives were almost all excellent. On the other hand, simple alkenes gave lower yields.

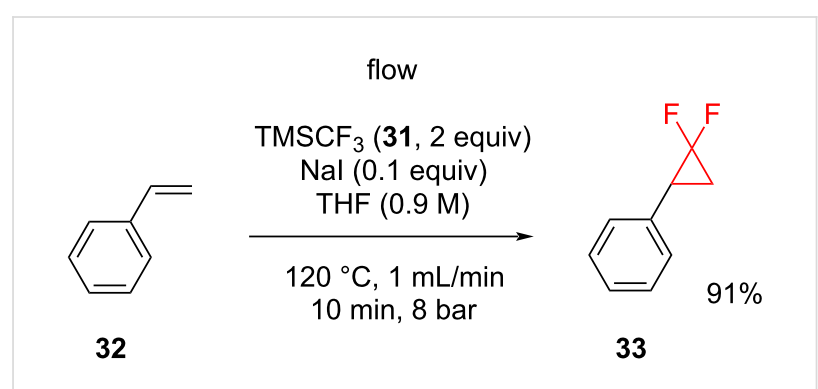

Scheme 15: gem-Difluorocyclopropanation of styrene (32) using difluorocarbene generated from $\mathrm{TMSCF}_{3}(\mathbf{3 1})$ under flow conditions.

The reaction of various functionalized alkenes with the $\mathrm{CF}_{3} \mathrm{SiMe}_{3}-\mathrm{NaI}$ system has been studied (Table 2). Difluorocarbene addition to $\alpha$-fluorostyrenes enabled the efficient synthe- 
Table 2: The synthesis of gem-difluorocyclopropanes using $\operatorname{TMSCF}_{3}(\mathbf{3 1})$ as the carbene source in combination with sodium iodide as initiator.

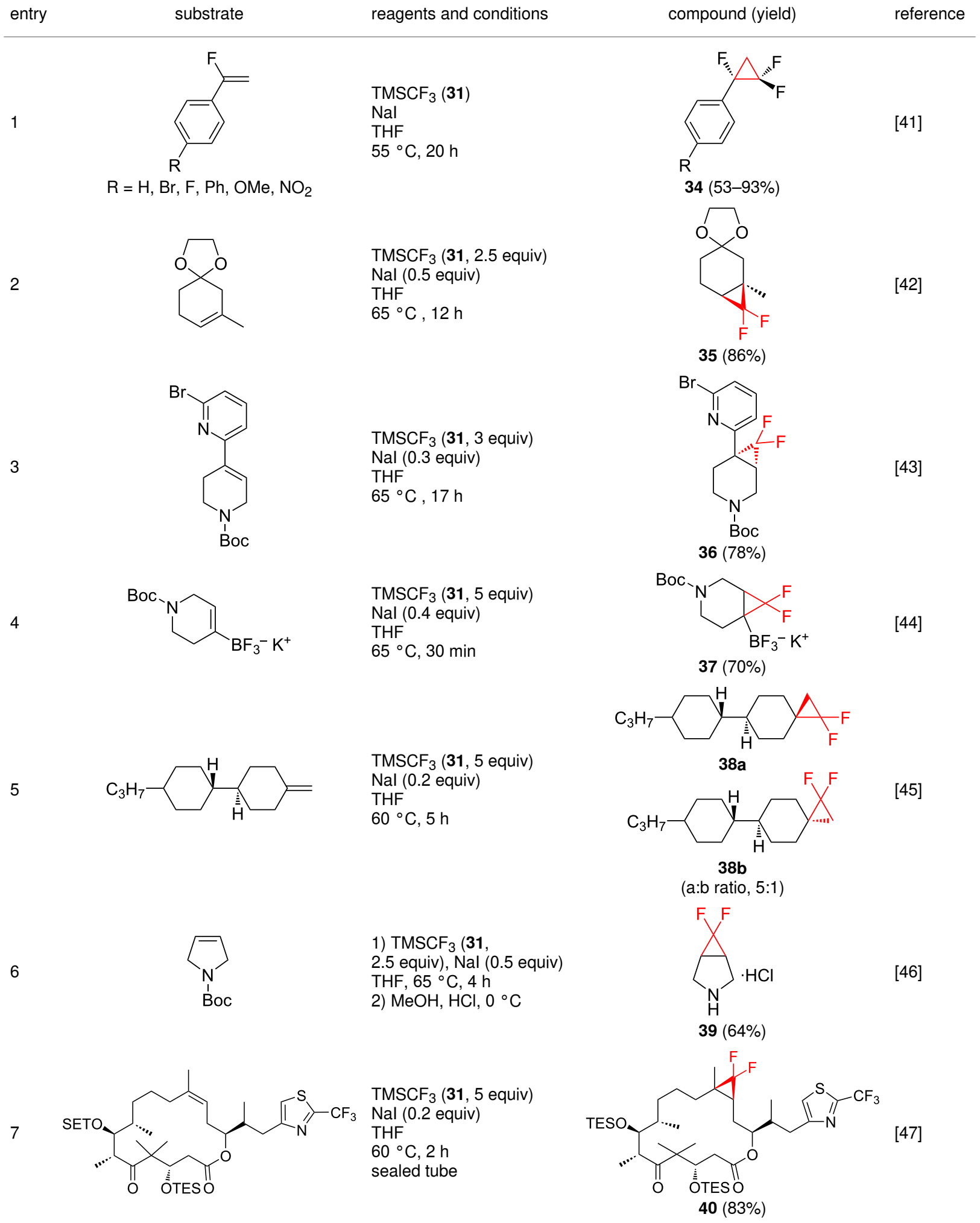

sis of trifluorocyclopropanes 34 [41]. The difluorocyclopropanation of protected cyclohexenone yielded cyclopropane $\mathbf{3 5}$ [42]. Difluorocyclopropane 36 was formed in high yield from the $\alpha$-bromopyridine-substituted $N$-Boc-3,4-dehydropiperidine. When the same reaction was attempted on the bromine-free analog, the yield was only $22 \%$ [43]. The difluorocyclopropana- 
tion of an alkenyl trifluoroborate using the $\mathrm{TMSCF}_{3}-\mathrm{NaI}$ system afforded the boronate derivative 37 [44]. The reagent was also used for the synthesis of organic spiro compounds, containing selectively fluorinated cyclopropanes $\mathbf{3 8 a}, \mathbf{b}$ [45], for the preparation of 6,6-difluoro-3-azabicyclo[3.1.0]hexane (39) (on a $10 \mathrm{~g}$ scale) [46], and of the epothilone B analog 40 [47] (Table 2).

The reagents (chlorodifluoromethyl)trimethylsilane $\left(\mathrm{ClCF}_{2} \mathrm{SiMe}_{3}\right.$ [48]) and (bromodifluoromethyl)trimethylsilane $\left(\mathrm{ClCF}_{2} \mathrm{SiMe}_{3}\right.$ [49]) have both been used for the difluorocyclopropanation and gave good yields in reactions with electron-rich alkenes. The formation of difluorocarbene was effected by heating the precursors in the presence of catalytic amounts of halide sources (e.g., tetramethylammonium chloride or tetrabutylammonium bromide). Compared with the difluoromethylenation protocols using TFDA (25), MDFA (30), or $\mathrm{TMSCF}_{3}$ (31), the application of $\mathrm{BrCF}_{2} \mathrm{SiMe}_{3}$ has been claimed to be safer and more convenient for large-scale application because of the avoidance of gaseous byproducts [49]. Other mild sources of difluorocarbene include trifluoro(trifluoromethyl)silane $\left(\mathrm{CF}_{3} \mathrm{SiF}_{3}\right.$ [50]) and difluorotris(trifluoromethyl)phosphorane $\left(\left(\mathrm{CF}_{3}\right)_{3} \mathrm{PF}_{2}[51]\right)$.

Difluorocarbene generation through the decomposition of hexafluoropropylene oxide upon heating: Hexafluoropropylene oxide (HFPO, 41) is an effective and cheap reagent for the difluorocyclopropanation of simple alkyl- and aryl-substituted alkenes [52]. It undergoes decomposition to form difluorocarbene (Scheme 16) at temperatures above $170{ }^{\circ} \mathrm{C}$ either under autoclave conditions or by gas-phase co-pyrolysis [53].

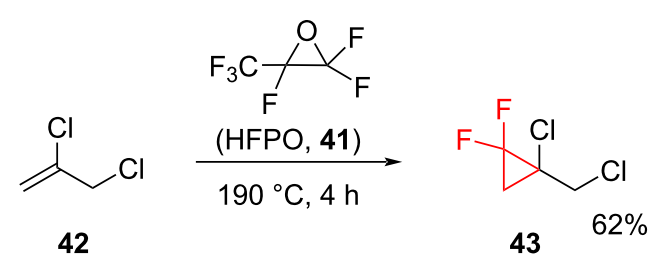

Scheme 16: Synthesis of a gem-difluorocyclopropane derivative using HFPO (41) as a source of difluorocarbene.

Photolytic generation of difluorocarbene: Difluorodiazirine (44) is a convenient photochemical source of difluorocarbene (Scheme 17). The compound readily produces difluorocarbene upon photolysis. $\mathrm{N}_{2}$ is the leaving group and it is good for LFP studies [54].

Furthermore, pyrolysis is also suitable for difluorocarbene generation from this reagent. Consequently, difluorocarbene is generated, when diazirine 44 is heated above $165^{\circ} \mathrm{C}$. Moreover,

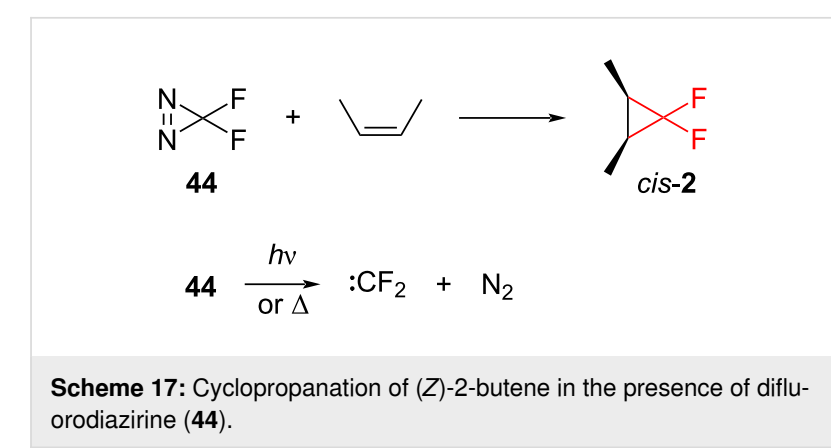

the reactions using $\mathbf{4 4}$ as a carbene source produce the difluorocyclopropanes in good yields [55]. As for the disadvantages, difluorodiazirine (44) is quite explosive.

\subsection{Difluorocarbene methods with organometallic sources}

Decomposition of phenyl(trifluoromethyl)mercury in the presence of sodium iodide: The preparation of difluorocyclopropanes using phenyl(trifluoromethyl)mercury $\left(\mathrm{PhHgCF}_{3}, \mathbf{4 5}\right.$, Seyferth's reagent) as a source of difluorocarbene, results in good yields of the products from both electron-rich and electron-poor alkenes [56]. The required decomposition of $\mathrm{PhHgCF}_{3}(\mathbf{4 5})$ can be achieved by refluxing in benzene in the presence of $\mathrm{NaI}$ (Scheme 18).

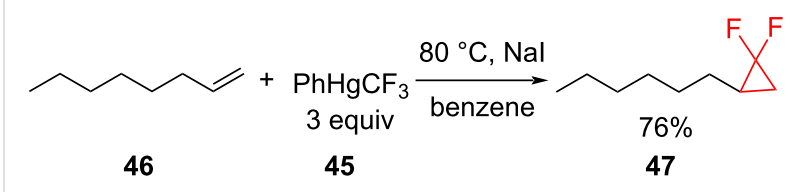

Scheme 18: The cyclopropanation of 1-octene (46) using Seyferth's reagent (45) as a source of difluorocarbene.

In addition to $\mathbf{4 5}$, two other organomercury compounds which have been shown to act as sources of difluorocarbene are iodo(trifluoromethyl)mercury $\left(\mathrm{IHgCF}_{3}\right)$ and bis(trifluoromethyl)mercury $\left(\mathrm{Hg}\left(\mathrm{CF}_{3}\right)_{2}\right)$ [57]. However, despite good synthetic conversions having been obtained with Seyferth's reagent [58] and the general insensitivity of organomercurials to air and moisture, the presence of mercury in all of these structures is a major drawback because organomercury compounds are extremely toxic and environmentally persistent.

Decomposition of trimethyl(trifluoromethyl)tin in the presence of sodium iodide: It is also possible to prepare difluorocyclopropanes from olefins and trifluoromethyl derivatives of tin such as trimethyl(trifluoromethyl)tin (48). There are two possible ways to obtain difluorocarbene from 48: thermal (at 140-150 ${ }^{\circ} \mathrm{C}, 20-44 \mathrm{~h}$ ) [59] and iodide ion induced (at $85^{\circ} \mathrm{C}$, 
$16 \mathrm{~h}$ ) (Scheme 19) [60]. The trapping with alkenes gave the expected cyclopropanes.

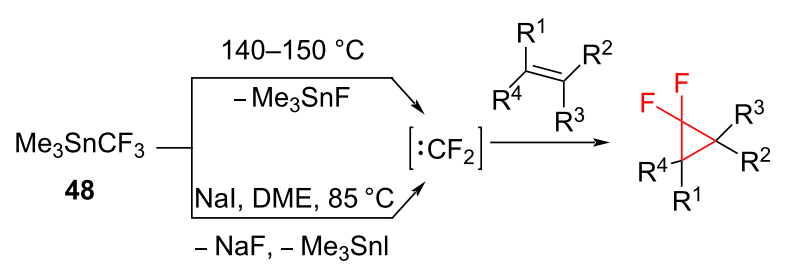

Scheme 19: Alternative approaches for the difluorocarbene synthesis from trimethyl(trifluoromethyl)tin (48).

The reaction of $\left(\mathrm{CH}_{3}\right)_{3} \mathrm{SnCF}_{3}$ (48) with $\mathrm{NaI}$ (1 equiv) occurred in 1,2-dimethoxyethane (Scheme 20) [60]. The difluorocarbene then added to cyclohexene (49) to form difluoronorcarane $\mathbf{5 0}$ with good yield. Under similar conditions tetramethylethylene afforded 1,1-difluorotetramethylcyclopropane (4).

$$
\begin{aligned}
& \text { II }+\left(\mathrm{CH}_{3}\right)_{3} \mathrm{SnCF}_{3}+\mathrm{Nal} \underset{\text { reflux, } 16 \mathrm{~h}}{\stackrel{\mathrm{MeOCH}_{2} \mathrm{CH}_{2} \mathrm{OMe}}{\longrightarrow}><} \\
& 49 \\
& 48 \\
& 50 \quad 89 \%
\end{aligned}
$$

Scheme 20: Difluorocyclopropanation of cyclohexene (49).

Trifluoromethyl derivatives of cadmium, bismuth, zinc, and gold: Bis(trifluoromethyl)cadmium (51) precipitates quantitatively as a white powder from the reaction of $\mathrm{CF}_{3} \mathrm{I}$ with $\mathrm{Cd}(\mathrm{Et})_{2}$ (molar ratio 2.5:1) (Scheme 21) in chloroform at $-40{ }^{\circ} \mathrm{C}$. A warming to $-5{ }^{\circ} \mathrm{C}$ was sufficient to liberate difluorocarbene, which was trapped by the addition to alkenes. Thus, cis-stilbene (52) gave the gem-difluorocyclopropane derivative $\mathbf{5 3}$ plus cadmium fluoride $[61,62]$. However, cadmium compounds are highly toxic and furthermore $\left(\mathrm{CF}_{3}\right)_{2} \mathrm{Cd}$ is pyrophoric in air and liable to explode upon warming to room temperature.

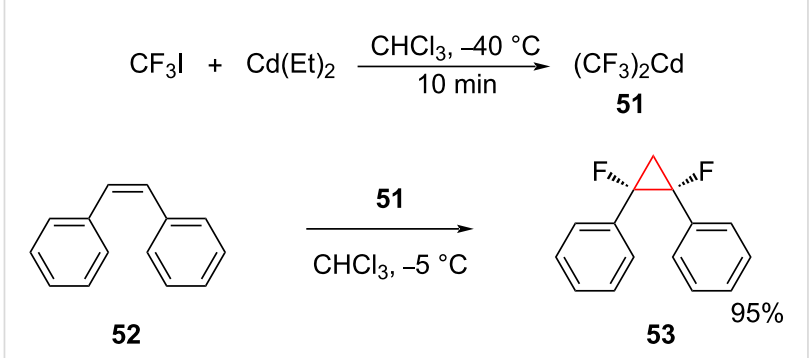

Scheme 21: Synthesis of difluorocyclopropane derivative 53 using bis(trifluoromethyl)cadmium (51) as the difluorocarbene source.

Tris(trifluoromethyl)bismuth (54) is also a source of difluorocarbene, that is generated during the reaction of $\mathbf{5 4}$ with $\mathrm{AlCl}_{3}$ and an alkene at $-20{ }^{\circ} \mathrm{C}$ (Scheme 22). The difluorocyclopropane $\mathbf{5 5}$ was obtained in $75 \%$ yield [63].

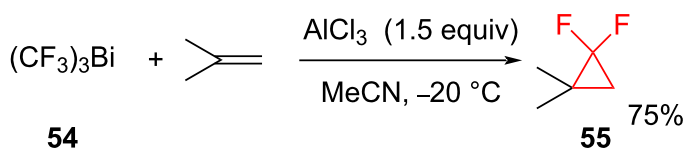

Scheme 22: Addition of difluorocarbene generated from tris(trifluoromethyl)bismuth (54).

A bis(trifluoromethyl)zinc reagent was employed as the difluorocarbene source for the gem-difluorocyclopropanation of alkenes or alkynes via thermal decomposition [64]. The reagent was generated from trifluoromethyl iodide $\left(\mathrm{CF}_{3} \mathrm{I}\right)$ and $\mathrm{Zn}$ dust (or $\mathrm{ZnEt}_{2}$ ) in 1,3-dimethyl-3,4,5,6-tetrahydro-2(1H)-pyrimidinone (DMPU) [65] and later isolated [66]. The reaction of $\mathrm{Zn}\left(\mathrm{CF}_{3}\right)_{2}$ (DMPU) $)_{2}$ (2 equiv) with styrenes proceeded efficiently in toluene to provide the difluorocyclopropanes $\mathbf{5 6}$ in 53-93\% yields (Scheme 23) [64].

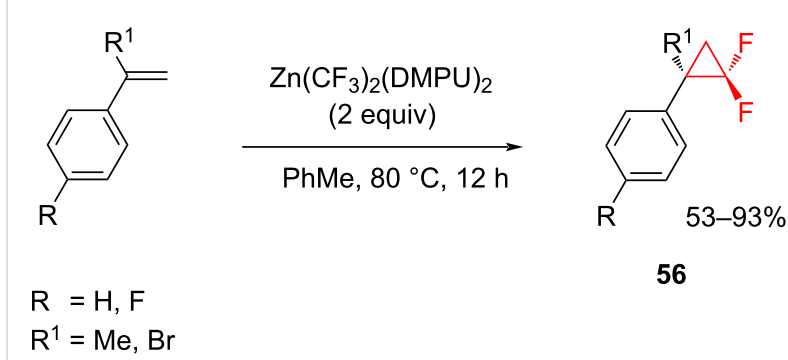

Scheme 23: Addition of a stable (trifluoromethyl)zinc reagent to styrenes.

Fürstner et al. [67] showed that (trifluoromethyl)gold(I)triphenylphosphine in dichloromethane can be used for the production of difluorocyclopropanes at low temperatures. The advantage of the method is its stereoselectivity. The disadvantages include the stoichiometric use of gold, low temperatures, process length (17 hours), and the low yields of products $(12-45 \%)$.

\subsection{Non-carbene methods}

Although the generation of difluorocyclopropanes often involved difluorocarbene, several non-carbene methods have also been developed. Taguchi and Okada developed a protocol for the preparation of 2,2-difluorocyclopropanecarboxylic acid derivatives 58 by the Michael addition of ester and amide enolates to 2,4,6-trimethylphenyl 4-bromo-4,4-difluorocrotonate (57) followed by an $\mathrm{Et}_{3} \mathrm{~B}$-initiated radical cyclization (Scheme 24) [68]. 


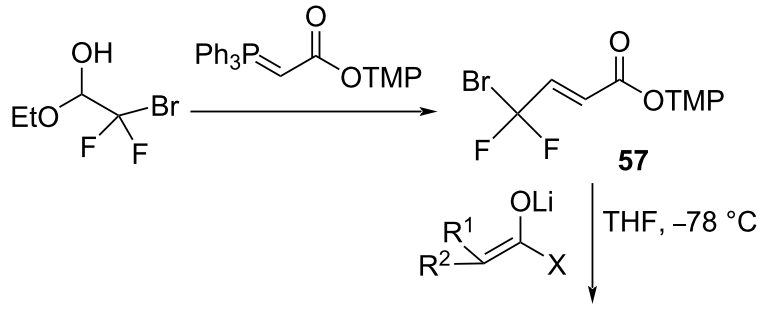

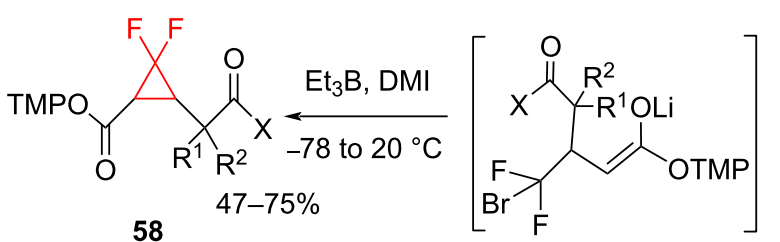

$$
\begin{aligned}
\mathrm{R}^{1}, \mathrm{R}^{2} & =\mathrm{H}, \text { Alk } \\
\mathrm{X} & =\mathrm{OR}, \mathrm{NR}_{2}
\end{aligned}
$$

Scheme 24: The preparation of 2,2-difluorocyclopropanecarboxylic acids of type 58 .

Furthermore, when the sodium salt of dimethyl malonate was used as the Michael donor the cyclopropane formation did not require $\mathrm{Et}_{3} \mathrm{~B}$ (Scheme 25).

$$
57+\mathrm{NaCH}\left(\mathrm{CO}_{2} \mathrm{Me}\right)_{2} \underset{\mathrm{rt}, 29 \mathrm{~h}}{\stackrel{\mathrm{THF}, \mathrm{DMI}}{\longrightarrow}} \underset{\mathrm{MeO}_{2} \mathrm{C}}{\mathrm{MeO}_{2} \mathrm{C}} \underbrace{\mathrm{O}}_{\mathbf{5 9}}
$$

Scheme 25: Difluorocyclopropanation via Michael cyclization.

The work was extended to include boron-free, diastereoselective versions incorporating $\mathrm{N}$-acylimidazolidinone chiral auxiliaries (Scheme 26).<smiles>CCOC(=O)OC1COC(=O)N1C(=O)/C=C/C(=O)OCc1ccccc1</smiles><smiles>CCOC[C@@H](C1C(C(=O)N2C(=O)OC[C@H]2Cc2ccccc2)C1(F)F)N(c1ccccc1)c1ccccc1</smiles>

Scheme 26: Difluorocyclopropanation using $N$-acylimidazolidinone 60.

\section{Cyclization reaction of phenylacetonitrile and 1,2-dibromo-}

1,1-difluoroethane: Kagabu et al. showed that the nitrile $\mathbf{6 3}$ could be obtained by the reaction of phenylacetonitrile $(\mathbf{6 1})$ with 1,2-dibromo-1,1-difluoroethane (62) using sodium amide as the base (Scheme 27) [69]. However, the yield of this reaction was only $10 \%$.

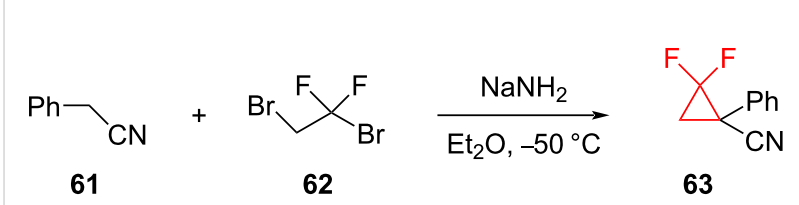

Scheme 27: Difluorocyclopropanation through the cyclization of phenylacetonitrile (61) and 1,2-dibromo-1,1-difluoroethane (62).

The gem-difluorocyclopropanes $\mathbf{6 5}$ were synthesized from the reaction of gem-difluoroolefins $\mathbf{6 4}$ and chloroform in an aqueous $40 \% \mathrm{NaOH}$ solution using the phase-transfer catalyst benzyltriethylammonium chloride (Scheme 28) [70,71]. Although difluorocarbene is not involved in the cyclopropanation step, this approach does employ dichlorocarbene.<smiles>[R]c1ccc(C(C)=C(F)F)cc1</smiles>

64

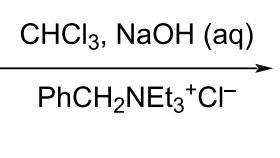

R

65
$\mathrm{R}=\mathrm{H}, \mathrm{Me}, \mathrm{Cl}$

Scheme 28: gem-Difluoroolefins 64 for the synthesis of functionalized cyclopropanes 65 .

\subsection{Transformation of functional groups}

gem-Difluorocyclopropanes easily undergo various transformations leading to the formation of a diversity of useful materials. Although gem-difluorocyclopropanes contain a strained ring, they are kinetically stable under the conditions employed for many synthetically important reactions. These include the catalytic hydrogenolysis of benzyl ethers $\left(\mathrm{H}_{2}, \mathrm{Pd}\right)$ [72], DIBAL-H reduction of esters to form alcohols [73], oxidative cleavage of vinyl groups to form carboxylic acids $\left(\mathrm{KMnO}_{4}\right)$ [74], and the conversion of the acids into amines using the Curtius rearrangement $\left(\mathrm{SOCl}_{2}\right.$, followed by $\mathrm{Me}_{3} \mathrm{SiN}_{3}$, thermolysis, and acid hydrolysis of the intermediate isocyanate, Scheme 29) [74]. Such transformations proceed with the conservation of the difluorocyclopropane unit and complement the methods for the cyclopropyl-ring synthesis discussed in the previous sections.

Generation of fluorinated methylenecyclopropanes: Fluorinated methylenecyclopropanes are of interest as Michael acceptors and as substrates for thermal rearrangements. As they are 


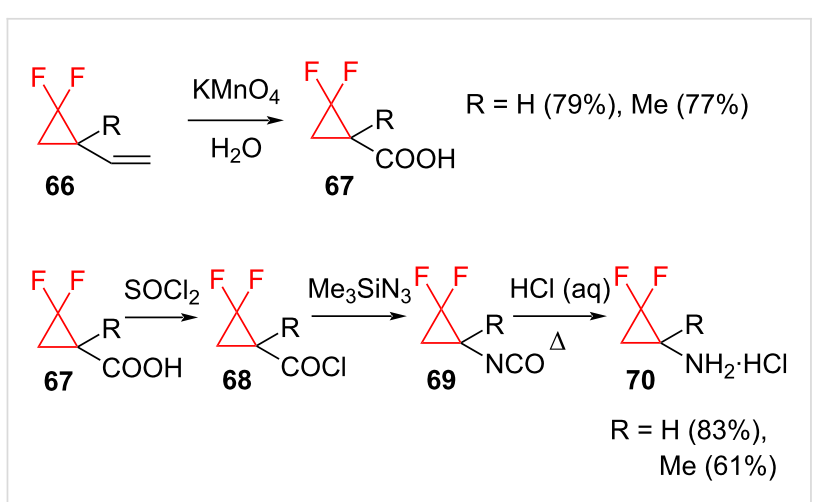

Scheme 29: Preparation of aminocyclopropanes $\mathbf{7 0 .}$

not readily available by difluorocarbene addition to allene derivatives, Taguchi et al. developed an alternative route to these compounds by selenoxide elimination (Scheme 30) [75]. Later, this approach was modified by Wang and co-workers [76].
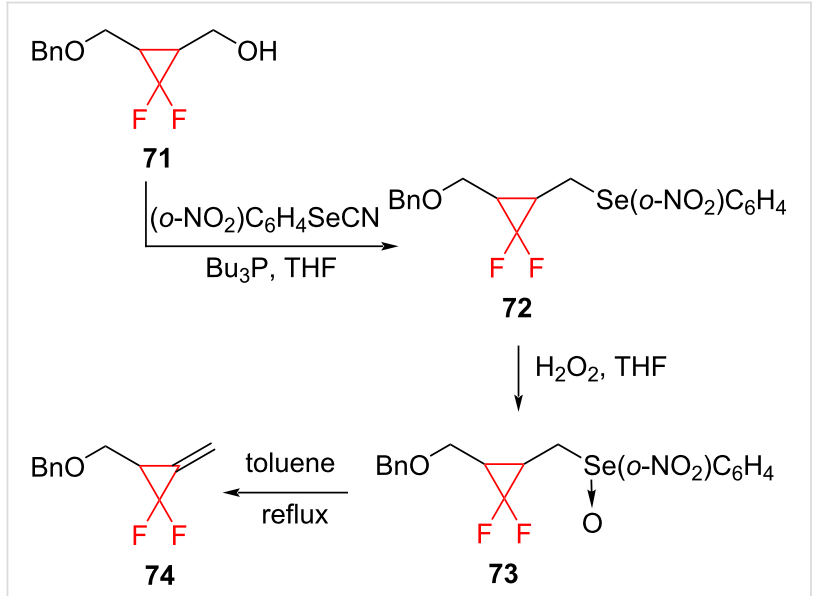

Scheme 30: Synthesis of fluorinated methylenecyclopropane $\mathbf{7 4}$ via selenoxide elimination.

It is also possible to remove the fluorine substituents from difluorocyclopropanes while preserving the three-membered ring. The reductive defluorination of the difluorocylopropane derivative 75 by the treatment with excess $\mathrm{NaBH}_{4}$ in hot DMSO (Scheme 31) gave the corresponding cyclopropane 76 [77] Caution is advised in view of a recent report that $\mathrm{NaBH}_{4}$ lowers the onset temperature for the thermal decomposition of DMSO [78].

The asymmetric difluorocyclopropanation has not yet been developed to the extent achieved for the epoxidation. Consequently, the enantioselective functional group interconversions on prochiral or racemic difluorocyclopropane and difluorocyclopropene derivatives have provided important ways of obtaining enantiomerically pure cyclopropanes. The key reactions in

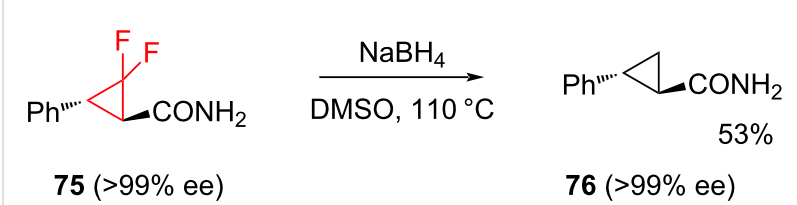

Scheme 31: Reductive dehalogenation of $(1 R, 3 R)-75$.

this context are the enzyme-catalyzed formation and hydrolysis of esters and the hydrogenation of difluorocyclopropenes $[73,79]$.

Enzymatic hydrolysis or esterification: The first example of the enzymatic resolution of gem-difluorocyclopropanes was reported by Itoh et al. [80]. The prochiral diacetate of cis-1,2-bis(hydroxymethyl)-3,3-difluorocyclopropane was converted into the corresponding monoacetate through Alcaligenes sp. lipasecatalyzed hydrolysis with $>99 \%$ enantiomeric excess.

Kirihara et al. have reported the synthesis of the separate enantiomers of 2,2-difluoro-1-aminocyclopropanecarboxylic acid, which are analogs of the naturally occurring 1-aminocyclopropanecarboxylic acid [81]. The authors obtained the chiral monoacetate intermediates $(R)-\mathbf{7 8}$ and $(S)-\mathbf{8 0}$ by lipase-catalyzed methods. The lipase-catalyzed asymmetric transesterification of prochiral diol $\mathbf{7 7}$ and the deacetylation of the prochiral diacetate 79 resulted in the formation of the $(R)$-monoacetate $(R)-\mathbf{7 8}$ and $(S)$-monoacetate $(S)$-80, respectively (Scheme 32 ). As for the transesterification, a high yield $(96.5 \%)$ and enantioselectivity $(91.3 \%$ ee) were obtained using lipase PS in benzene. In the case of the deacetylation, the use of Amano PS lipase in acetone gave a high yield (86.2\%), enantioselectivity (91.7\% ee), and smooth hydrolysis.

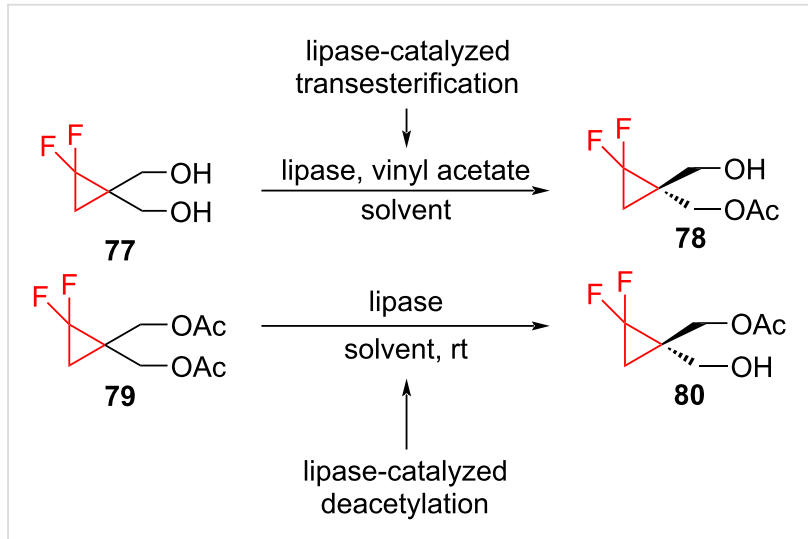

Scheme 32: Synthesis of chiral monoacetates by lipase catalysis.

Wang et al. reported the enantioselective biotransformations of geminally difluorinated cyclopropanecarbonitriles and amides 
in 2004 [77]. They transformed gem-difluorocyclopropane derivatives with the help of a soil microorganism, Rhodococcus sp. AJ270, which provided a very effective nitrile hydratase-amidase-containing biocatalytic system and showed a high chemo-, regio-, and enantioselectivity in the hydrolysis of nitriles and dinitriles.

The biocatalytic transformations of nitrile $\mathbf{8 1}$ (Scheme 33) supplied an effective route to optically active 2,2-difluorosubstituted 3-phenylcyclopropanecarboxylic acid $\mathbf{8 2}$ and amide $\mathbf{8 3}$ in both enantiomeric forms (Scheme 33). The biotransformation of the gem-difluorocyclopropane $\mathbf{8 1}$ produced good results for both the rate and yield. The $(1 S, 3 S)$-acid $\mathbf{8 2}$ and $(1 R, 3 R)$-amide $\mathbf{8 3}$ were synthesized in $52 \%$ yield with $53 \%$ ee and $32 \%$ yield with $>99 \%$ ee, respectively.

The biotransformation of gem-difluorocyclopropanecarboxamide $( \pm$ )-83 (Scheme 34 ) occurred rapidly and under mild conditions to give ( $1 R, 3 R$ )-amide $\mathbf{8 3}$ ( $46 \%$ yield, $>99 \%$ ee) and $(1 S, 3 S)$-acid 82 (51\% yield, $87 \%$ ee).

Enantioselective hydrogenation of difluorocyclopropenes: Recently, Mikami and co-workers reported the enantioselective hydrocupration of difluorocyclopropenes in the presence of chiral diphosphine ligands using stoichiometric hydride sources that included polymethylhydrosiloxane (PMHS) and organoboranes (Scheme 35) [79].

Cossy and co-workers have achieved the catalytic asymmetric transfer hydrogenation with isopropanol as reductant, in conjunction with a Noyori-Ikariya ruthenium-based homogeneous catalyst (Scheme 36) [73].

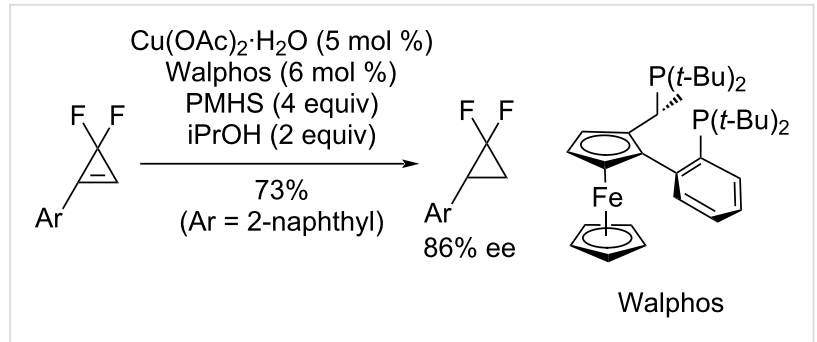

Scheme 35: Hydrogenation of difluorocyclopropenes through enantioselective hydrocupration.

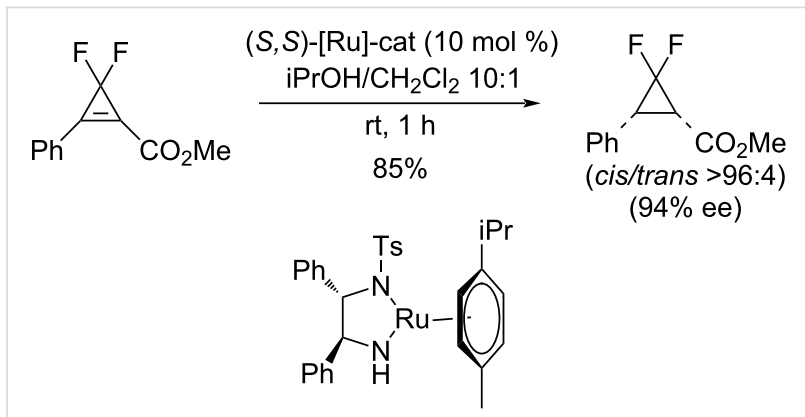

$(S, S)-[R u]-c a t$

Scheme 36: Enantioselective transfer hydrogenation of difluorocyclopropenes with a Ru-based catalyst.

\section{Reactions of difluorocyclopropane and its derivatives}

Difluorocyclopropanes are synthetically useful substrates for a variety of reactions such as thermal rearrangements, carbocation, carbanion, and radical chemistry. Furthermore, gem-difluorocyclopropanes readily go through carbonylation, dehalogenation, and annulation, resulting in various useful materials.

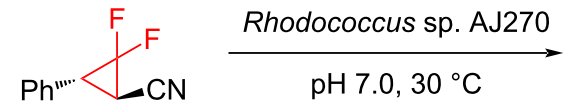

$( \pm)-81$

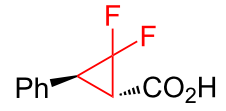

82

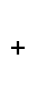<smiles>NC(=O)[C@H]1[C@@H](P)C1(F)F</smiles>

83 $32 \%(>99 \%$ ee $)$

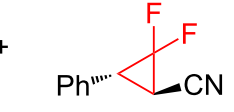

81

$10 \%(6 \%$ ee $)$

Scheme 33: Transformation of ( \pm )-trans-81 using Rhodococcus sp. AJ270.<smiles>NC(=O)C1C([PH+])C1C(F)(F)F</smiles>

$( \pm)-83$

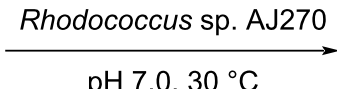

$\mathrm{pH} 7.0,30^{\circ} \mathrm{C}$<smiles>NC(=O)[C@@H]1[C@@H](c2ccccc2)C1(F)F</smiles>

$(1 R, 3 R)-83$

$46 \%(>99 \%$ ee $)$<smiles>O=C(O)[C@H]1[C@@H](P)C1(F)F</smiles>

$(1 S, 3 S)-82$

$51 \%(87 \%$ ee $)$

Scheme 34: Transformation of ( \pm )-trans-83 using Rhodococcus sp. AJ270. 


\subsection{Thermal rearrangements}

The substitution of hydrogen with fluorine in cyclopropane leads to a significant weakening of the $\mathrm{C}-\mathrm{C}$ bond opposite to the fluorine atom. A consequence of this is the tendency of fluorocyclopropanes, and in particular gem-difluorocyclopropanes, to undergo various transformations initiated by a homolytic $\mathrm{C}-\mathrm{C}$ bond breaking.

Thermal stereomutation: In 1975, Staricco and co-workers described the thermal isomerization of trans-1,2-dichloro-3,3difluorocyclopropane (84) (Scheme 37) [82].<smiles>FC1(F)C(Cl)C1Cl</smiles>

84$$
\mathrm{C}
$$

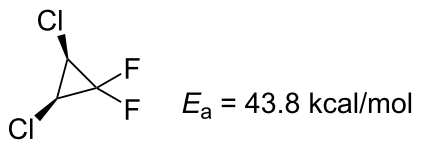

85

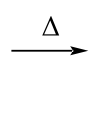

Scheme 37: The thermal transformation of trans-1,2-dichloro-3,3-difluorocyclopropane (84).

Further research in this area was performed by the groups of Jefford [83] and Dolbier [84], who studied the 1,1-difluoro-2,3dimethylcyclopropanes 86 and 87 (Scheme 38).

$$
\sum_{86}^{\longrightarrow} \rightleftharpoons \sum_{\mathrm{Me}}^{\mathrm{F}} \rightleftharpoons \begin{array}{r}
E_{\mathrm{a}}=49.7 \mathrm{kcal} / \mathrm{mol} \\
\Delta H_{0}=-0.7 \mathrm{kcal} / \mathrm{mol}
\end{array}
$$

Scheme 38: cis-trans-Epimerization of 1,1-difluoro-2,3-dimethylcyclopropane.

Dolbier found that geminal fluorine substituents lowered the activation energies for both cis-trans-isomerization and for the transformation of vinylcyclopropanes into cyclopentenes. Both processes could occur by a $\mathrm{C}-\mathrm{C}$-bond homolysis to form a diradical. Computational studies by Gety, Hrovat, and Borden indicated that there would be a preference for disrotation at $\mathrm{C} 2$ and C3 during stereomutation in 1,1-difluorocyclopropanes [85]. An important feature in the fluorinated system was the stabilization of the intermediate 2,2-difluorotrimethylene radicals due to the conjugation of the radical centers with the $\sigma^{*}$-orbital of C-F bond, which can be represented by a dipolar resonance structure containing the 2-fluoroallyl cation and fluoride anion (Scheme 39).

A subsequent comparison of the rates of racemization with those of epimerization confirmed experimentally the preference for coupled disrotatory motions in the opening and closing of 2,3-dialkyl-1,1-difluorocyclopropanes (Scheme 40) [86].

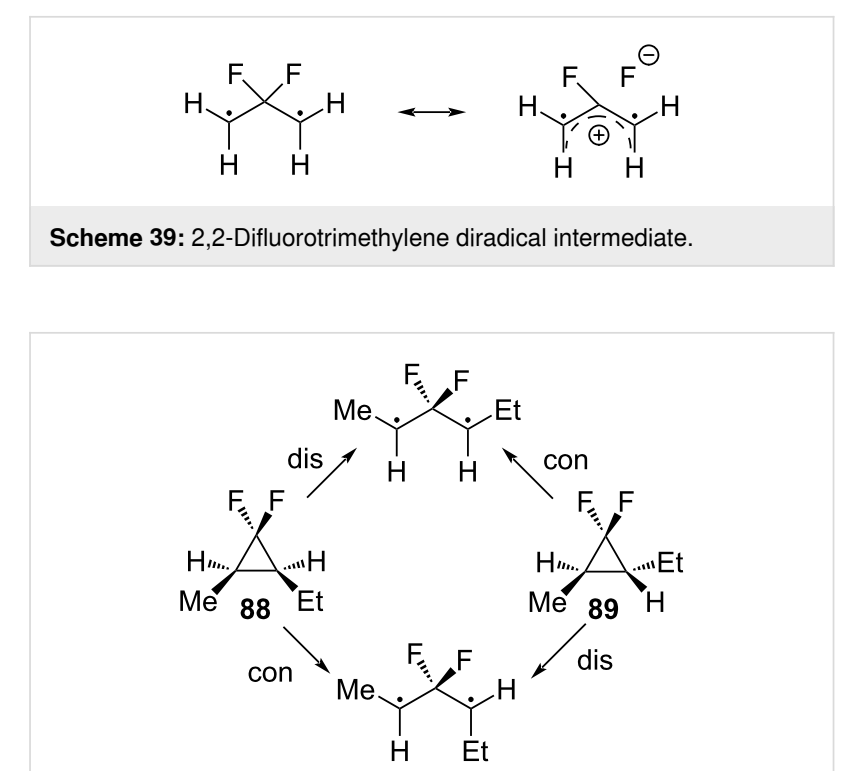

Scheme 40: Ring opening of stereoisomers 88 and 89

Vinylcyclopropane rearrangements: O'Neal and Benson examined the influence of fluorine substituents on the kinetics of the vinylcyclopropane-to-cyclopentene rearrangement [87]. They noted the effect of an additional strain (approximately $5 \mathrm{kcal} / \mathrm{mol}$ per fluorine atom) in raising the kinetic reactivity of difluorocyclopropanes and lowering the temperature required for the rearrangement. Furthermore, another effect of the geminal substitution was a weakening of the bond opposite to the $\mathrm{CF}_{2}$ fragment by $8-10 \mathrm{kcal} / \mathrm{mol}$.

Dolbier et al. studied the thermal rearrangements of 2,2difluoro-1-alkenylcyclopropanes 90-92 (Scheme 41) [88]. All three compounds underwent a highly regioselective cleavage of the $\mathrm{C} 1-\mathrm{C} 3$ bond. Hence, the major products of all rearrangements were produced via [1,3]-sigmatropic shifts (Scheme 41).

The products were the result of the breaking of the $\mathrm{C}-\mathrm{C}$ bond opposite to the $\mathrm{CF}_{2}$ moiety, which was followed by the recyclization of the intermediate diradical (Scheme 42). The activation energy for the rearrangement of $\mathbf{9 0}$ was lower by $9.4 \mathrm{kcal} / \mathrm{mol}$ than for the parent hydrocarbon system 92. The activation energy of the trans-isomer 91 was greater than that of cis-isomer $91(>6 \mathrm{kcal} / \mathrm{mol})$, because of the need to attain a cisoid conformation prior to the rearrangement.

The thermal vinylcyclopropane rearrangement of ethyl trans-3(2,2-difluoro-3-phenylcyclopropyl)acrylate $(\mathbf{9 3})$ proceeded at $100{ }^{\circ} \mathrm{C}$, resulting in the difluorinated cyclopentene 94 with the substituents oriented trans to each other (Scheme 43) [89]. The cis-isomer 95 was unable to rearrange directly to a cyclopentene and first isomerized to give 93. Alkenyldifluorocyclo- 


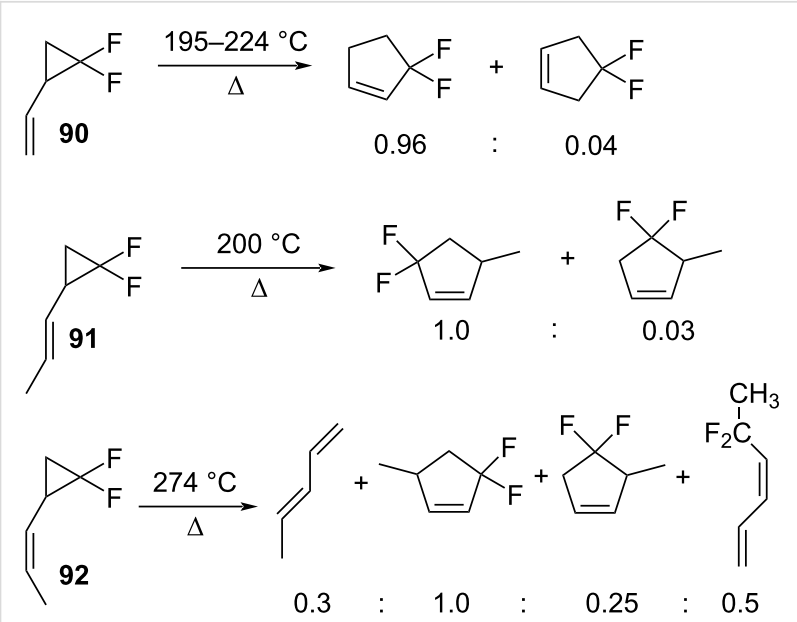

Scheme 41: [1,3]-Rearrangement of alkenylcyclopropanes 90-92.

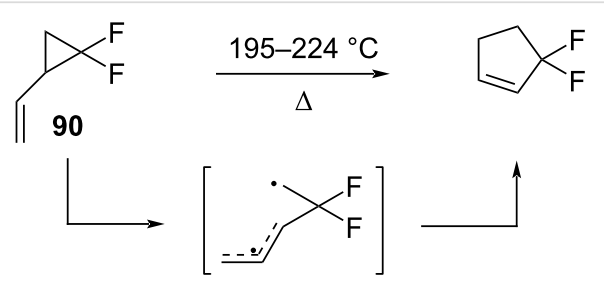

Scheme 42: Thermolytic rearrangement of 2,2-difluoro-1-vinylcyclopropane (90).

propanes that were derived from 2-siloxybutadienes underwent analogous rearrangements to afford 1-siloxy-5,5-difluorocyclopentenes [90].<smiles>CCOC(=O)C=CC1C(c2ccccc2)C1(F)F</smiles>

93<smiles>C=C</smiles><smiles></smiles>

Scheme 43: Thermal rearrangement for ethyl 3-(2,2-difluoro)-3phenylcyclopropyl)acrylates $\mathbf{9 3}$ and $\mathbf{9 5}$

The radical ring-opening polymerization (RROP) provides a synthetic route to fluoropolymers, which are useful materials [91]. The RROP of gem-difluorovinylcyclopropane (90) gave mainly the polymer with an unsymmetrical repeating unit, by the cleavage of the $\mathrm{C} 2-\mathrm{C} 3$ bond in the ring (Scheme 44, path a).
However, $10 \%$ of the symmetrical product originating from a $\mathrm{C} 1-\mathrm{C} 2$ bond cleavage (path b) were also observed.

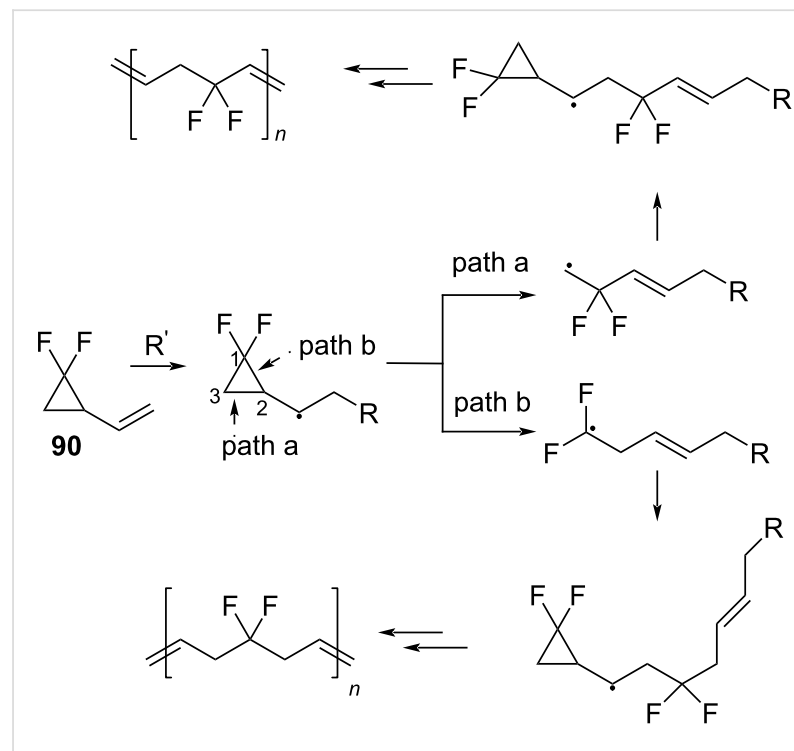

Scheme 44: Possible pathways of the ring opening of 1,1-difluoro-2vinylcyclopropane.

Methylenecyclopropane rearrangements: Although gemdifluoromethylenecyclopropanes ( $\mathrm{F}_{2} \mathrm{MCPs}$ ) have poor accessibility, there has been much interest in their thermal rearrangements.

Dolbier examined the rearrangement of 1,1-difluoro-2-methylenecyclopropane (96) (Scheme 45) [92]. At $210^{\circ} \mathrm{C}$ the rate of cleavage of the proximal bond was only 3.8 times faster than for the analogous hydrocarbon. It was also observed that the equilibrium lay significantly in favor of the rearranged product $\mathbf{9 7}$, which was by $1.9 \mathrm{kcal} / \mathrm{mol}$ more stable.

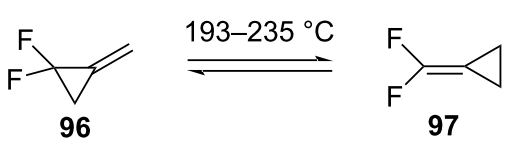

Scheme 45: Equilibrium between 1,1-difluoro-2-methylenecyclopropane (96) and (difluoromethylene)cyclopropane 97.

The thermal ring opening of the tosyl-substituted 1,1-difluoro2,2-dimethyl-3-methylenecyclopropane 98 led to the thermodynamically more stable products 99 and 100, respectively (Scheme 46) [93].

Spiropentane rearrangements: Gajewsky found that the rearrangement of the hydrocarbon spiropentane to form methylenecyclobutane occurred with the cleavage of the $\mathrm{C} 1-\mathrm{C} 2$ bond 


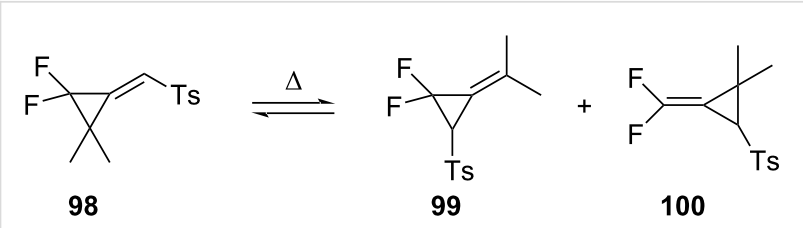

Scheme 46: Ring opening of substituted 1,1-difluoro-2,2-dimethyl-3methylenecyclopropane $\mathbf{9 8}$

[94]. Dolbier then used deuterium labeling to study the analogous reaction of 1,1-difluorospiropentane (101) (Scheme 47) [95]. The cleavage of the $\mathrm{C} 1-\mathrm{C} 2$ bond that is proximal to the fluorine resulted in the formation of two isomeric methylenecyclobutane derivatives $\mathbf{1 0 2}$ and $\mathbf{1 0 3}$ by a radical cyclization (Scheme 47). The minor product 102 underwent a fast rearrangement to produce the major product 103. An alternative pathway, that involved the cleavage of the C4-C5 bond in $\mathbf{1 0 1}$, also led to the product $\mathbf{1 0 3}$.

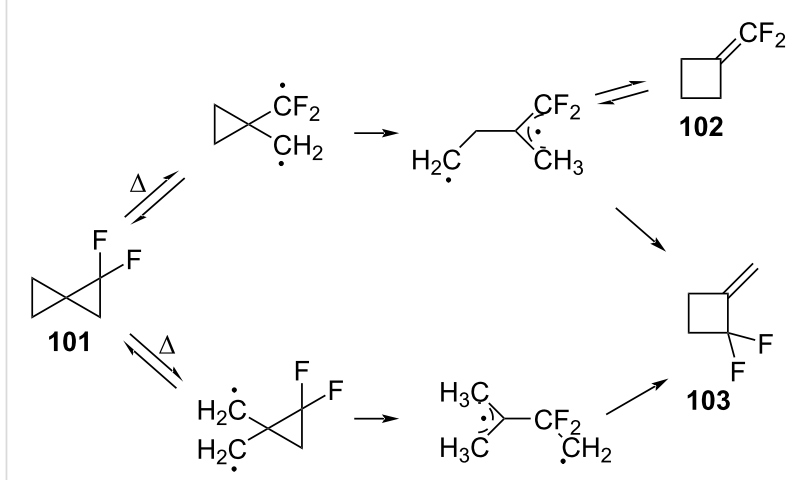

Scheme 47: 1,1-Difluorospiropentane rearrangement.

\subsection{Ring opening of gem-difluorocyclopropanes by external reagents}

gem-Difluorocyclopropanes have unique properties that arise from the strain of the cyclopropane ring combined with the electronic properties of fluorine. Many of the reactions involve ring-opening processes, the course of which can be controlled by the selection of the reagents and catalysts. These have an influence on the mechanism and regioselectivity of the $\mathrm{C}-\mathrm{C}$ bond cleavage. Although there are several different mechanisms for ring-opening reactions, in most cases there is a cleavage of the most weakened $\mathrm{C}-\mathrm{C}$ bond due to the fluorine effect. This $\mathrm{C}-\mathrm{C}$ bond is opposite to the fluorinated fragment (the distal bond) [2].

The ring-opening reactions of $(2,2$-difluorocyclopropyl)methyl systems: Dolbier investigated the acetolysis of tosylates $\mathbf{1 0 4}$ and $\mathbf{1 0 5}$ (Scheme 48) [96]. The difference between compounds $\mathbf{1 0 4}$ and $\mathbf{1 0 5}$ is the presence of a methyl sub- stituent in $\mathbf{1 0 5}$, which is associated with a difference in the regioselectivity of the $\mathrm{C}-\mathrm{C}$ bond cleavage. The dissociation of the tosylate $\mathbf{1 0 4}$ to generate a cyclopropylmethyl carbocation $\mathbf{A}$ was accompanied by the cleavage of the proximal bond to form homoallylic products. The regioselectivity of the ring opening was attributed to the stabilization of the developing cationic center by the $+\mathrm{M}$ effect of the fluorine atoms. The formation of the 2,2-difluorohomoallyl cation or 3,3-difluorocyclobutyl cation did not occur as a result of the strong destabilization by the $-\mathrm{I}$ effect of the fluorine atoms [96]. On the other hand, the principal ring-opened product of $\mathbf{1 0 5}$ derives from the cleavage of the distal bond. In this case, the methyl substituent was superior to the two fluorine atoms in stabilizing an adjacent cationic center in $\mathbf{B}$. Therefore, the ring opening proceeded via the disruption of the $\mathrm{C}-\mathrm{C}$ bond opposite to the $\mathrm{CF}_{2}$ fragment and the formation of a 2,2-difluorohomoallyl cation.

Cleavage of the distal bond. Ring opening of gem-difluorocyclopropyl ketones: The gem-difluorocyclopropyl ketones such as $\mathbf{1 0 6}$ and $\mathbf{1 0 8}$ underwent nucleophilic ring-opening reactions induced by thiolate nucleophiles. A distal bond cleavage occurred regioselectively via difluoroenolate intermediates that could participate in subsequent elimination and substitution of fluoride, leading to good yields of the fluorine-free products 107 and 109 (Scheme 49) [97,98].

$\mathrm{Xu}$ and Chen studied the acid-catalyzed hydrolysis of gemdifluorocyclopropyl acetals $\mathbf{1 1 0}$ to form 2-aryl-3-fluorofurans 112 (Scheme 50) [99]. The reaction could proceed either via the intermediacy of the gem-difluorocyclopropyl ketone 111 (path a) or by the direct rearrangement of the protonated acetal (path b). Recently, the group of Amii has reported the conversion of 1-benzoyl-2,2-difluoro-3-phenylcyclopropane and its derivatives into 3-fluoro-2,5-diphenylfuran derivatives following the brief exposure to triflic acid ( 2 equiv) in cold dichloromethane [100].

Dolbier et al. described the ring opening of 2,2-difluorocyclopropyl ketones 113 (Scheme 51) [101]. The reactions were mediated by acids and an ionic liquid. 3-Bromo-2,2-difluoropropyl ketones 114 were formed in good to excellent yields by an overall addition of $\mathrm{HBr}$ accompanied by a distal bond cleavage.

Dolbier et al. also studied the $\mathrm{MgI}_{2}$-facilitated reactions of aryl2,2-difluorocyclopropyl ketones 113 with imines 115, which led to alkylideneazetidines 116 (Scheme 52) [102]. The $\mathrm{MgI}_{2}$ acted as a Lewis acid and reducing agent, effecting the distal $\mathrm{C}-\mathrm{C}$ bond cleavage in 113a to form an allenyl ketone, or an equivalent fluoro,iodo-enone species, either of which could then have added to the imine $\mathbf{1 1 5}$ and led to the observed product. Only 

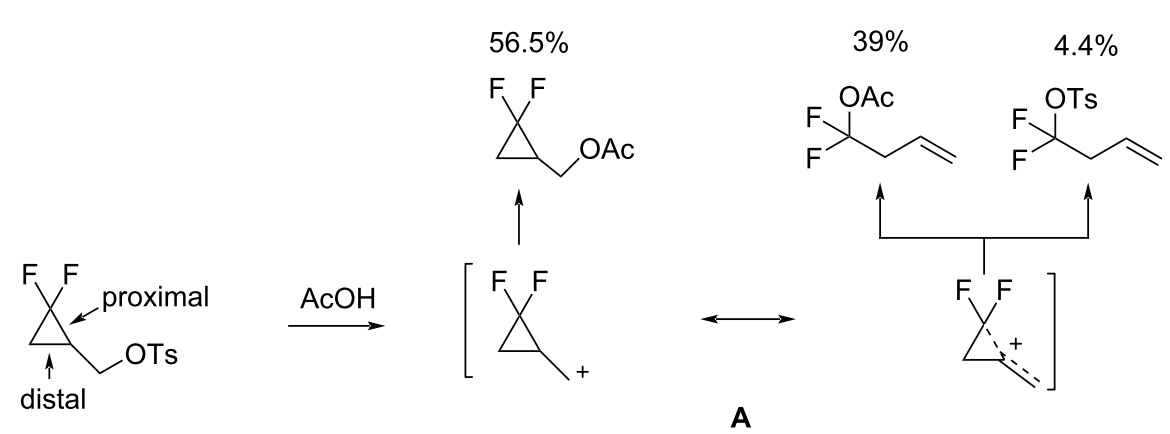

104

A

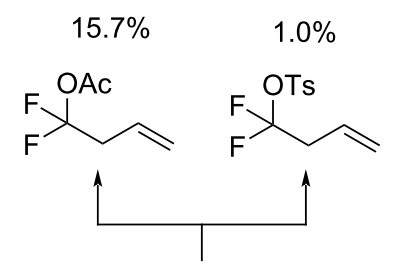

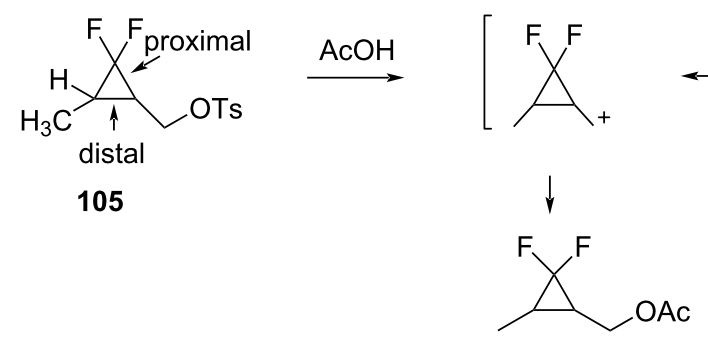

$44.6 \%$

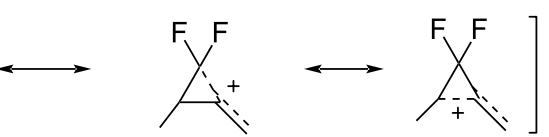

B

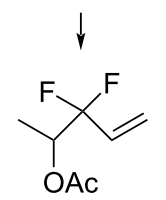

$38.6 \%$

Scheme 48: Acetolysis of (2,2-difluorocyclopropyl)methyl tosylate (104) and (1,1-difluoro-2-methylcyclopropyl)methyl tosylate (105).

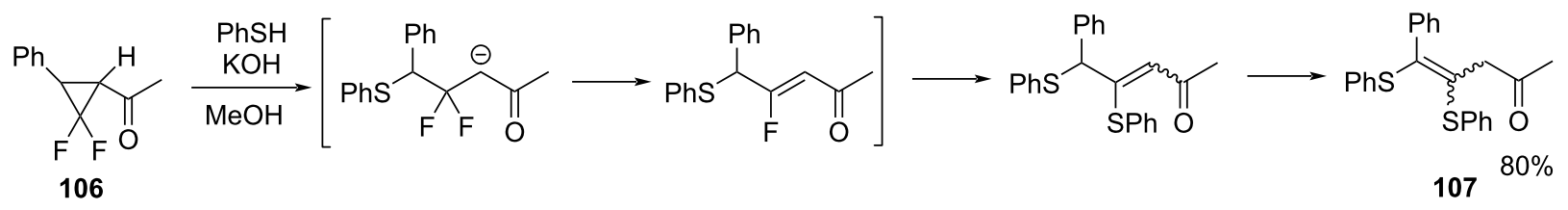<smiles>CC(=O)C1(C)C(c2ccccc2)C1(F)F</smiles>

108<smiles>Nc1ccccc1S</smiles><smiles>COC(O)O</smiles><smiles>C/C(=C1/Nc2ccccc2SC1c1ccccc1)C(C)C</smiles>

109

$73 \%$ diarylimines were utilized in this study, largely because of their ease of preparation and stability.

Ring-opening reaction of $\mathbf{g e m}$-difluorocyclopropylstannanes: Konno and co-workers reported the conversion of cyclo- propylstannanes 117 into monofluoro derivatives of allylic alcohols, ethers, esters, and amines (121, Scheme 53) [103]. They proposed that an initial tin-lithium exchange was followed by a $\beta$-elimination of $\mathrm{LiF}$ to form the intermediate cyclopropenes 119. The ring opening of the latter then generated the vinylcar- 
<smiles>[R]C1=CC(F)(F)C([Al])O1</smiles>

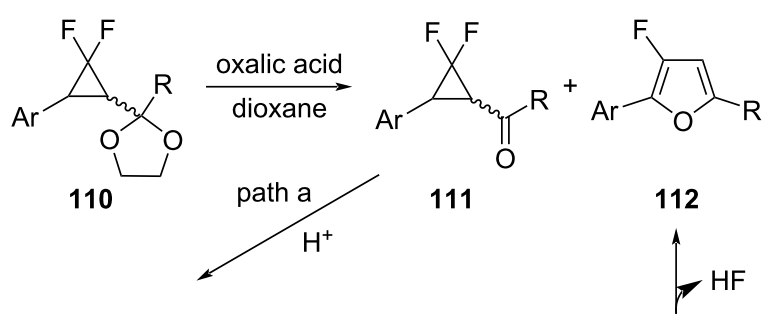<smiles>[R]C1=CC(F)(F)C([Al]C(C)C)O1</smiles>

Scheme 50: Hydrolysis of gem-difluorocyclopropyl acetals 110.

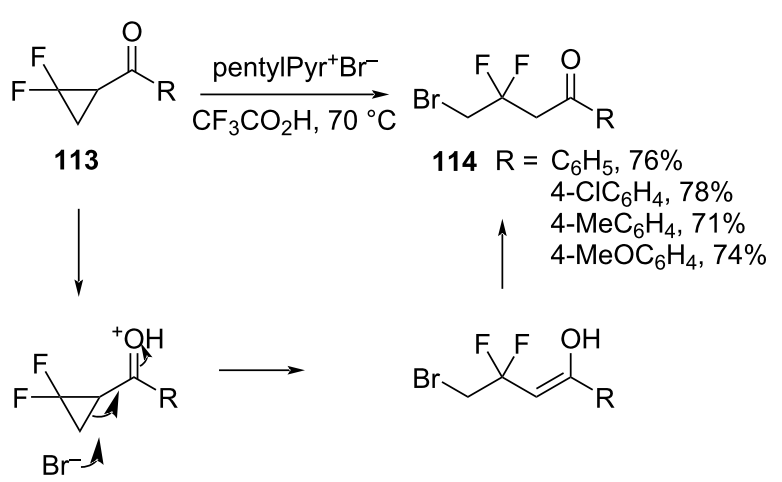

Scheme 51: Ring-opening reaction of 2,2-difluorocyclopropyl ketones 113 in the presence of ionic liquid as a surrogate of $\mathrm{HBr}$ reagents.

benes 120. The carbenes $\mathbf{1 2 0}$ could then insert into the $\mathrm{O}-\mathrm{H}$ and $\mathrm{N}-\mathrm{H}$ bonds of water, alcohols, carboxylic acids, and amines to form the observed products $\mathbf{1 2 1}$.

1,1-Difluoro-2-siloxy-2-vinylcyclopropane (122) was subjected to a fluoride-catalyzed ring opening to afford 1-fluorovinyl

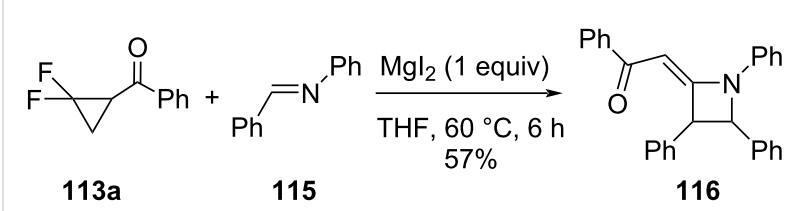

Scheme 52: Ring opening of gem-difluorocyclopropyl ketones 113a by $\mathrm{Mgl}_{2}$-initiated reaction with diarylimines 115.

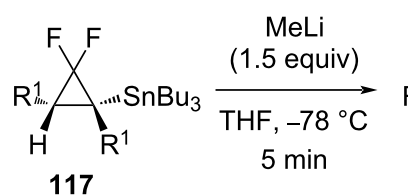

117

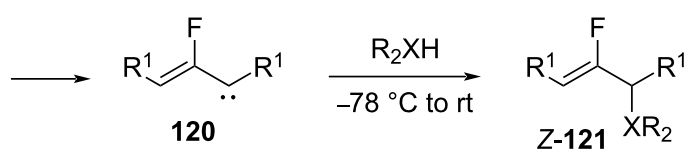

120

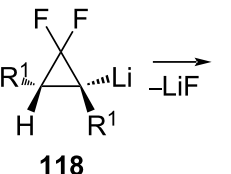<smiles>[R1]C1C([R10])C1F</smiles>

119
$\mathrm{R}_{2} \mathrm{XH}=\mathrm{ROH}, \mathrm{RCO}_{2} \mathrm{H}, \mathrm{RNH}_{2}$

Scheme 53: Ring-opening reaction of gem-difluorocyclopropylstannanes 117

vinyl ketones such as $\mathbf{1 2 3}$. These compounds underwent a Lewis acid-catalyzed Nazarov cyclization with the strong silylating agent $\mathrm{Me}_{3} \mathrm{Si}^{+} \mathrm{B}(\mathrm{OTf})_{4}{ }^{-}$to afford the corresponding 2-fluorocyclopentenone derivatives, e.g., compound $\mathbf{1 2 4}$ (Scheme 54) [37,90].

Radical-mediated ring-opening reaction: The photochemical iodine atom-transfer ring opening of 1,1-difluoro-2-(1iodoalkyl)cyclopropanes $\mathbf{1 2 5 a - c}$ was initiated by hexabutylditin (Scheme 55) [104]. The (E)-difluorohomoallyl iodides 128a-c were isolated in yields ranging from 52 to $60 \%$. The proposed reaction pathway involved the formation of the cyclopropylmethyl radical $\mathbf{1 2 6}$, which rapidly underwent ring opening to give the homoallyl radical 127.

Itoh et al. discovered the generation of 1,6-dienes $\mathbf{1 2 9}$ via the ring opening of bromomethyl-bearing gem-difluorocyclopropanes $\mathbf{1 3 0}$ due to the reaction with allyltributylstannane in<smiles></smiles>

122

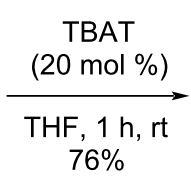
$76 \%$<smiles>C=C(F)C(=O)/C=C/c1ccccc1</smiles>

123

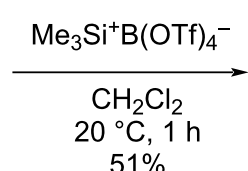

$51 \%$<smiles>O=C1CC(c2ccccc2)C=C1F</smiles>

124 


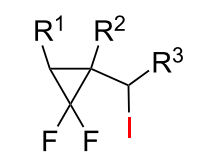

$125 a-c$
$\underset{\mathrm{Bu}_{3} \mathrm{SnSnBu}_{3} \text { (0.1 equiv), hv }}{\mathrm{PhH}, \mathrm{rt}}$

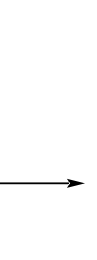<smiles>[R]C=C([R])C(F)(F)C([R])I</smiles>

$128 a-c$ 128a $R^{1}=H, R^{2}=\mathrm{CH}_{3}, \mathrm{R}^{3}=\mathrm{PhCH}_{2} \mathrm{CH}_{2}(60 \%)$;

128b $R^{1}=R^{2}=H, R^{3}=P^{2} \mathrm{Ph}_{2} \mathrm{CH}_{2}(60 \%)$;

128c $R^{1}=\mathrm{PhCH}_{2} \mathrm{CH}_{2}, \mathrm{R}^{2}=\mathrm{R}^{3}=\mathrm{H}(52 \%)$
126

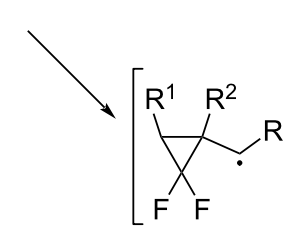

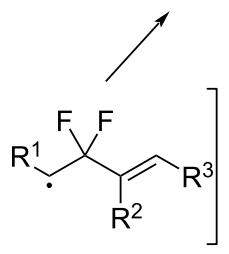

127

Scheme 55: lodine atom-transfer ring opening of 1,1-difluoro-2-(1-iodoalkyl)cyclopropanes 125a-c.
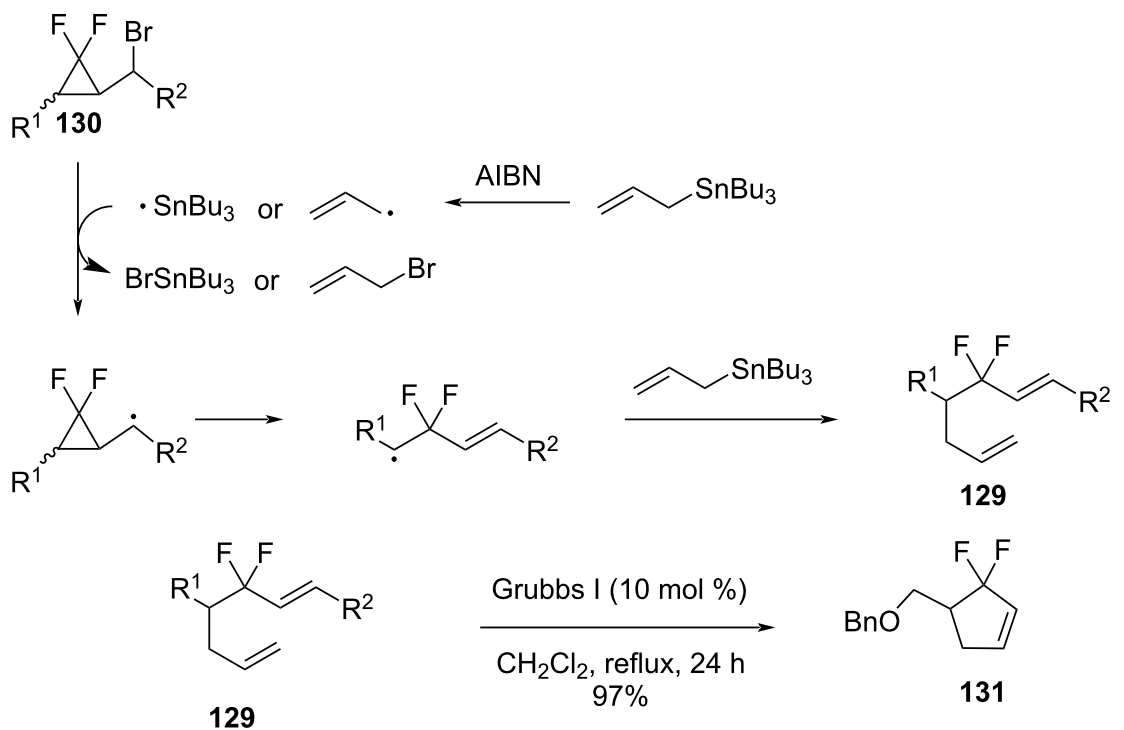

$\mathrm{R}^{1}=\mathrm{OBn}, \mathrm{R}^{2}=\mathrm{H}$

Scheme 56: Ring opening of bromomethyl gem-difluorocyclopropanes 130 and formation of gem-difluoromethylene-containing cycloalkenes 131 .

the presence of AIBN (Scheme 56) [105]. The ring opening of the intermediate cyclopropylmethyl radical occurred with a cleavage of the distal $\mathrm{C}-\mathrm{C}$ bond. The reaction proceeded regioselectively and in high yields. There was no difference observed between cis and trans-isomers in terms of the reactivity and yields. The resultant dienes 129 were used in ring-closing metathesis reactions to furnish gem-difluorocyclopentenes 131 in good to excellent yields [106].

A convenient route to 2,2-difluoro-homoallylic alcohols $\mathbf{1 3 3}$ occurred by photo-irradiative aerobic oxidation (Scheme 57) [107]. The reaction proceeded by the light-mediated ringopening reaction of gem-difluorocyclopropane $\mathbf{1 3 2}$ in the presence of an organic dye and the subsequent aerobic oxidation by an amine.

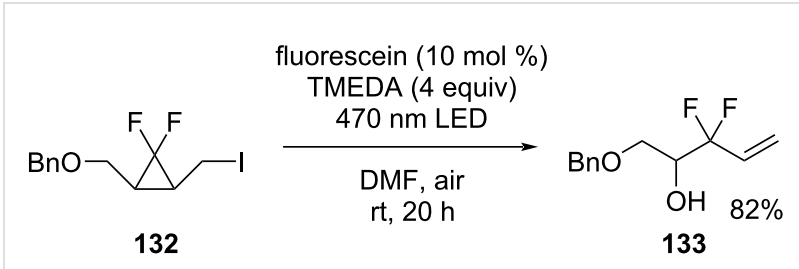

Scheme 57: Ring-opening aerobic oxidation reaction of gem-difluorocyclopropanes 132.

Single-electron oxidants such as cerium ammonium nitrate or $\mathrm{K}_{2} \mathrm{~S}_{2} \mathrm{O}_{8}$ were used for the regiospecific ring opening of the simple gem-difluorocyclopropanes 134 (Scheme 58). The brominative ring-opening reactions of compounds $\mathbf{1 3 4}$ gave good yields of the dibromo derivatives $\mathbf{1 3 5}$ when $\mathrm{KBr}$ was em- 
ployed in a $\mathrm{DCM} / \mathrm{H}_{2} \mathrm{O} 1: 1(\mathrm{v} / \mathrm{v})$ mixed solvent. Alternatively, the bromohydroxylation and bromoamidation were also achieved simply by changing the solvent system [108]

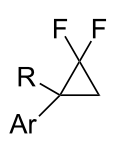

134

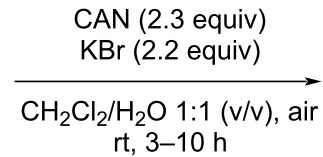

rt, 3-10 h

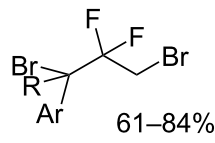

135
Scheme 58: Dibrominative ring-opening functionalization of gem-difluorocyclopropanes 134.

Stereodivergent sets of conditions were devised to produce stereodefined $(E, E)$ - and $(E, Z)$-fluorodienals $\mathbf{1 3 6}$ and $\mathbf{1 3 7}$ in high yields by a base-induced cleavage of the weak distal bond of gem-difluorocyclopropyl acetaldehydes 138 (Scheme 59) [109].

Xiao et al. studied the ring-opening reactions of difluoro(methylene)cyclopropane $\mathbf{1 3 9}$ with halogens and amines [110,111]. A number of fluorine-containing compounds were synthesized in this way. The reaction with bromine proceeded through the breaking of the distal bond of the cyclopropyl ring affording the final fluorine-containing compound 140 (Scheme 60) [111].

Cleavage of the proximal bond: Cheng investigated the ringopening reactions of difluoro(methylene)cyclopropanes $\left(\mathrm{F}_{2} \mathrm{MCPs}\right)$ of type 139 (Scheme 61 ) [112]. The heating with iodine in the presence of $\mathrm{CuI}$ resulted in the cleavage of the proximal $\mathrm{C} 2-\mathrm{C} 3$ bond and the overall addition of a molecule of iodine to give products $\mathbf{1 4 1}$ in high yields.

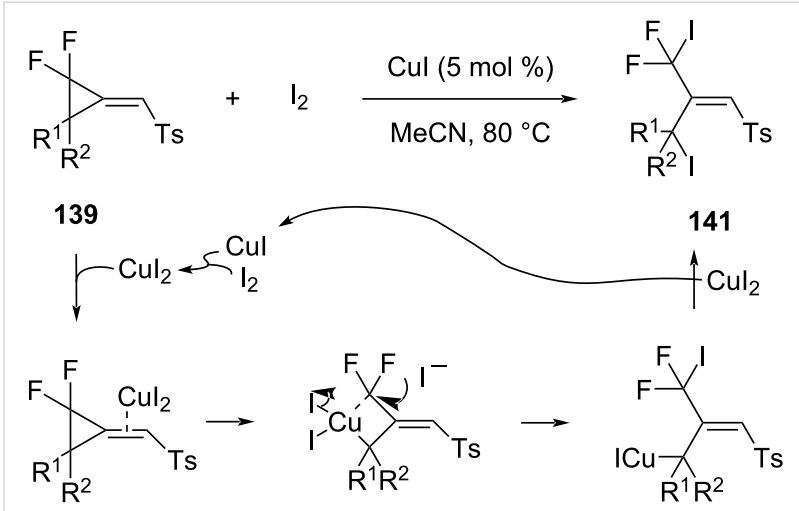

Scheme 61: Thermal rearrangement of $\mathrm{F}_{2} \mathrm{MCP} 139$ and iodine by $\mathrm{Cul}$ catalysis.

Xiao et al. described a direct synthesis of 2-fluoropyrroles 142 (Scheme 62) [113]. The reaction involved the gem-difluorocyclopropyl ketones 143 and nitriles 144. It was proposed that the protonation of the ketone with triflic acid led to a partial ring opening of the gem-difluorocyclopropyl ketone to generate a carbocation-like center that was stabilized by the two attached fluorine atoms. The nucleophilic attack of the nitrile, followed by cyclization and aromatization could then give the pyrrole derivatives 142 .

Later, Xiao et al. performed another ring-opening reaction of gem-difluorocyclopropyl ketones $\mathbf{1 4 3}$, this time mediated by $\mathrm{BX}_{3}(\mathrm{X}=\mathrm{F}, \mathrm{Cl}, \mathrm{Br}$, Scheme 63) [114]. In this transformation,<smiles>O=C/C=C/C(F)=C\Br</smiles>

$(E, E)-\mathbf{1 3 6}$

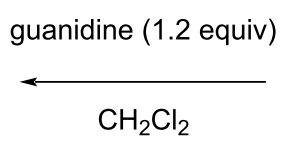

$\mathrm{CH}_{2} \mathrm{Cl}_{2}$

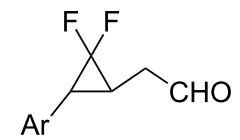

138

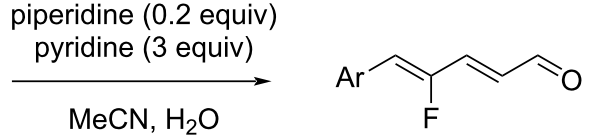

$(E, Z)-\mathbf{1 3 7}$

Scheme 59: The selective formation of $(E, E)$ - and $(E, Z)$-fluorodienals 136 and 137 from difluorocyclopropyl acetaldehydes 138.

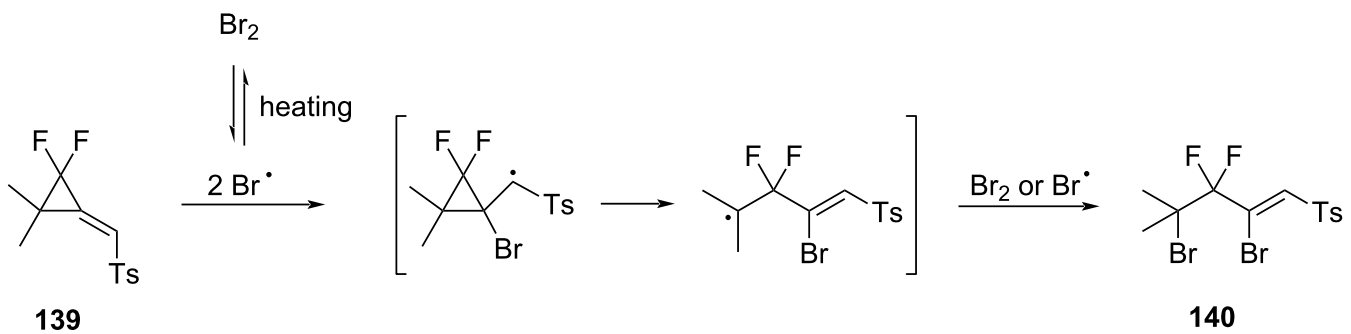

Scheme 60: Proposed mechanism for the reaction of difluoro(methylene)cyclopropane 139 with $\mathrm{Br}_{2}$. 


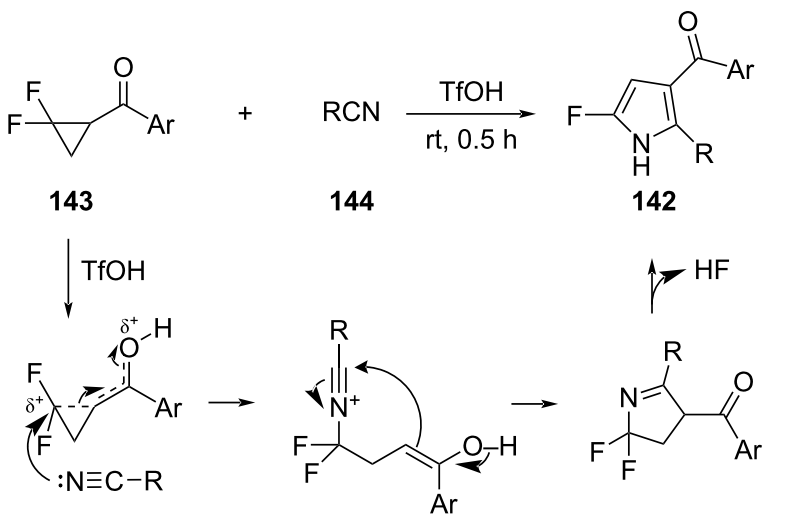

Scheme 62: Synthesis of 2-fluoropyrroles 142.

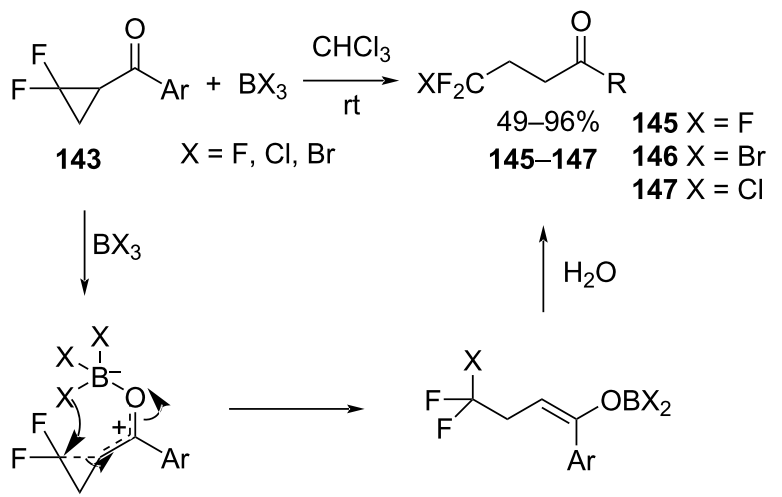

Scheme 63: Ring opening of gem-difluorocyclopropyl ketones 143 mediated by $\mathrm{BX}_{3}$.
$\mathrm{BX}_{3}$ played a dual role as both a Lewis acid catalyst and a source of the halide ion nucleophile. This reaction resulted in the generation of the trifluoromethyl ketones 145 and halodifluoromethyl ketones 146 and 147 in high yields. As in the previous reaction, a cleavage of the proximal bond accompanied the nucleophilic ring opening. The authors concluded that reactions mediated by weak acids resulted in the cleavage of the distal bond. This occurred by an $\mathrm{S}_{\mathrm{N}} 2$ attack at the less hindered carbon of the cyclopropyl group. In contrast to this, reactions mediated by strong acids led to the cleavage of the proximal bond by the generation of fluorine-stabilized carbocations $\left(\mathrm{S}_{\mathrm{N}} 1\right.$ mechanism) [114].

The Friedel-Crafts reaction of 2,2-difluorocyclopropanecarbonyl chloride (148) with arenes $149 \mathrm{a}-\mathbf{c}$ was accompanied by a proximal bond scission promoted by the strong Lewis acid $\mathrm{AlCl}_{3}$. This led to the formation of aryl 3-chloro-3,3-difluoropropyl ketones 150a-c (Scheme 64) [115].

The gem-difluorocyclopropyl ketone $\mathbf{1 0 6}$ underwent a proximal bond cleavage in the reaction with methanolic $\mathrm{KOH}$ and methyl 4-oxo-2-phenylpentanoate was obtained in $85 \%$ yield after acid workup (Scheme 65) [97,98]. This contrasts with the previously discussed (Scheme 49) distal bond cleavage of ketone $\mathbf{1 0 6}$ in reactions with thiolate nucleophiles.

It is likely that an elimination of HF from 106 to form a monofluorocyclopropene intermediate took place under the more strongly basic conditions. This would facilitate the substitution of both fluorine atoms by methoxy groups prior to the ring opening, with the $+\mathrm{M}$ effect of the two $\mathrm{MeO}$ groups facilitating heterolysis of the proximal $\mathrm{C}-\mathrm{C}$ bond.
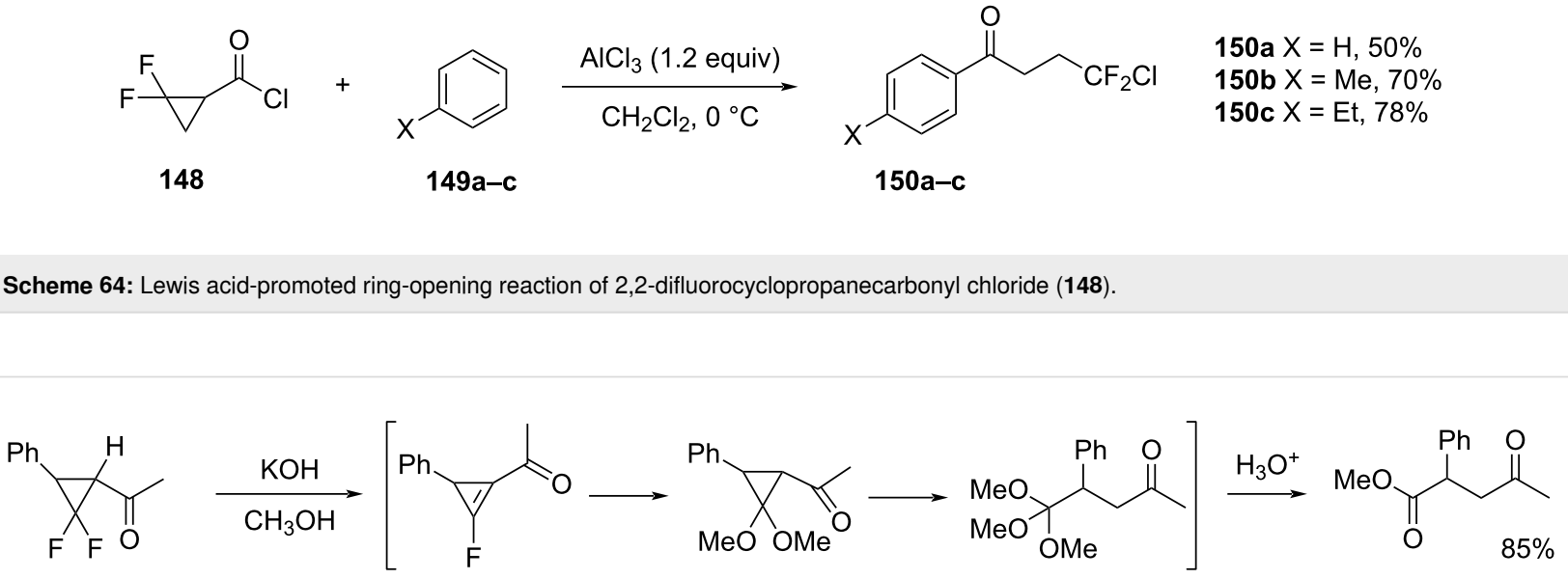
Transition metal-catalyzed ring-opening reactions: Recently, the possibilities of using gem-difluorocyclopropanes in the synthesis of fluoroalkenyl-substituted compounds (monofluoroalkenes) have been actively studied. Great opportunities exist for the use of transition metal catalysis.

The catalytic hydrogenolysis of 1,1-difluoro-3-methyl-2phenylcyclopropane (151) led to the regioselective C2-C3 distal bond cleavage by the use of either palladium(II) oxide or Raney nickel as the catalyst (Scheme 66) [116]. Butylbenzene (152) and 2-fluoro-1-phenylbutane (153) were the main products, although the unsaturated intermediates 154 and 155 were also detected. The contribution of the fluorine substituents to the lengthening and weakening of the $\mathrm{C} 2-\mathrm{C} 3$ bond of the cyclopropane ring appeared to dictate the regioselectivity.

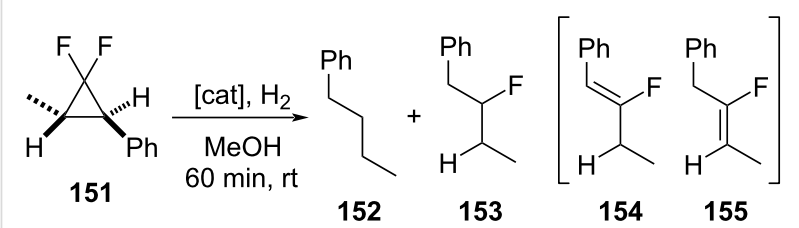

cat composition (\%)

$\begin{array}{lrr}\text { PdO } & 23 & 39 \\ \text { Raney nickel } & 49 & 6\end{array}$

Scheme 66: Hydrogenolysis of 1,1-difluoro-3-methyl-2-phenylcyclopropane (151).

Monofluoroalkenes 157 were formed from the reductive ring opening of gem-difluorocyclopropanes 156 with dimethylamine-borane and catalyzed by nickel(II) fluorido complexes (Scheme 67) [117].

1-Trimethylsiloxy-2,2-difluorocyclopropanes $\mathbf{1 5 8}$ underwent a silver-promoted ring opening by the nucleophilic heteroaromatic 1,2-dimethylindole (159) to give aryl-substituted 2-fluoroalkenyl compounds $\mathbf{1 6 0 a}, \mathbf{b}$ (Scheme 68) [118]. An initial fluoride abstraction by $\mathrm{Ag}^{+}$triggered the distal $\mathrm{C}-\mathrm{C}$ bond cleavage to form an intermediate allylic cation which was the electrophile in a Friedel-Crafts reaction with 159. The subsequent desilylation of the Friedel-Crafts product gave an $\alpha$-fluorinated ketone intermediate which then reacted with a second

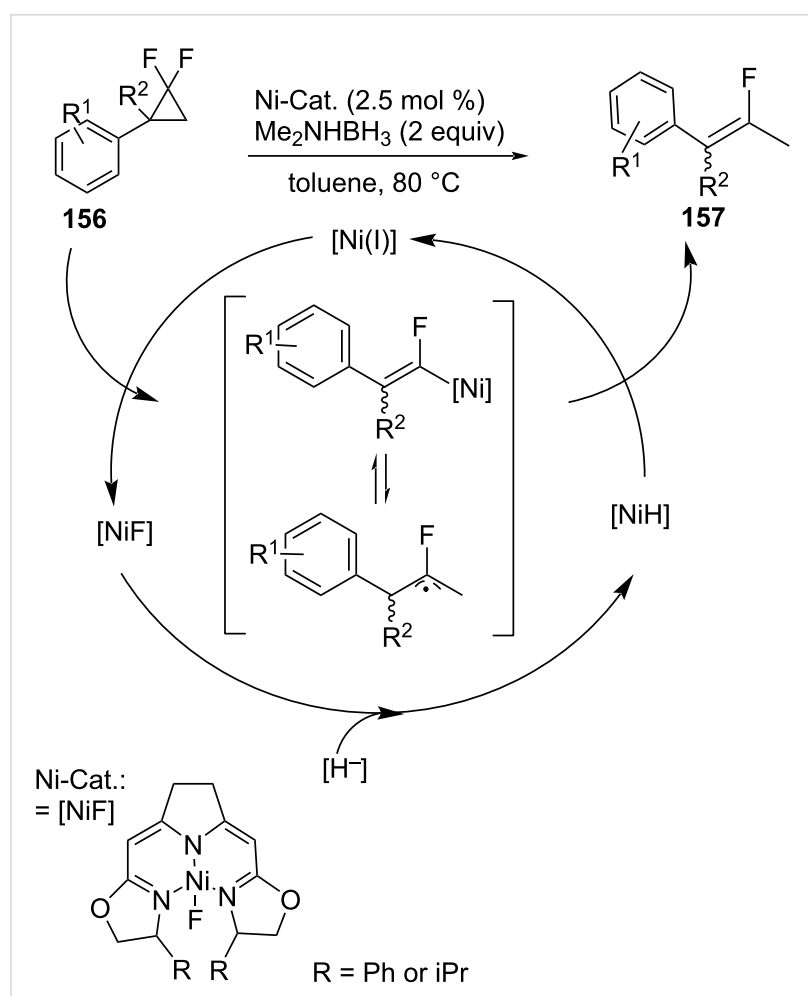

Scheme 67: Synthesis of monofluoroalkenes 157.

equivalent of $\mathbf{1 5 9}$ in a (Z)-stereoselective, chelation-controlled process.

Fu et al. presented a practical method to synthesize monofluorinated allylic scaffolds via a Pd-catalyzed C-C activation/C-F cleavage (Scheme 69) [119]. This ring opening of the gemdifluorocyclopropanes 161 occurred with both O- and $\mathrm{N}$-nucleophiles. The resulting 2-fluorinated allylic products $\mathbf{1 6 2}$ were obtained in good yields and with high $(Z)$-selectivity. The proposed mechanism involved the oxidative addition of the distal $\mathrm{C}-\mathrm{C}$ bond to palladium, followed by a nucleophilic attack at the less hindered carbon atom of a 2-fluorinated palladium- $\pi$ allyl complex.

Other examples of Pd-catalyzed ring-opening reactions of gemdifluorocyclopropanes $\mathbf{1 6 1}$ are presented in Scheme 70. The first approach involved a Suzuki cross-coupling of the gem-
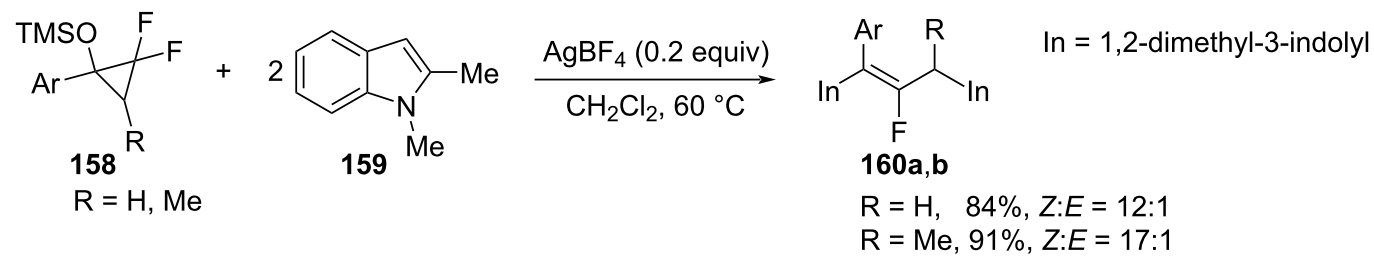

Scheme 68: The stereoselective Ag-catalyzed defluorinative ring-opening diarylation of 1-trimethylsiloxy-2,2-difluorocyclopropanes 158. 


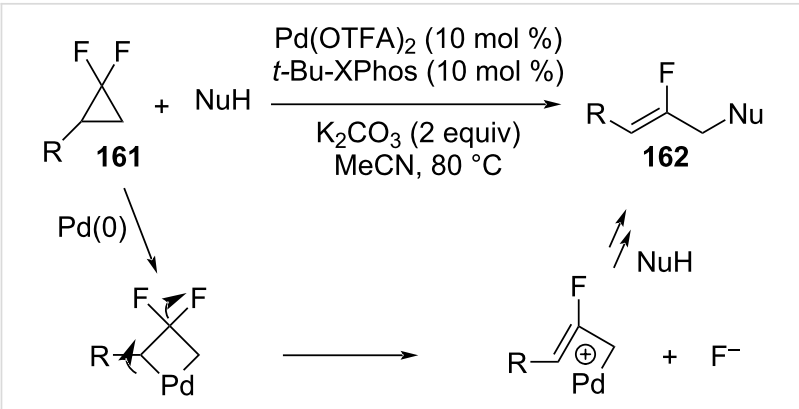

Scheme 69: Synthesis of 2-fluorinated allylic compounds 162.

fluorinated cyclopropanes $\mathbf{1 6 1}$ with boronic acids which afforded the monofluoroalkenes $\mathbf{1 6 3}$ [120]. Very recently, the groups by Gong and Fu [121] studied the Pd-catalyzed alkynylation of cyclopropanes 161 with terminal alkynes that led to the formation of the isomeric fluorinated enynes 164 and $\mathbf{1 6 5}$.

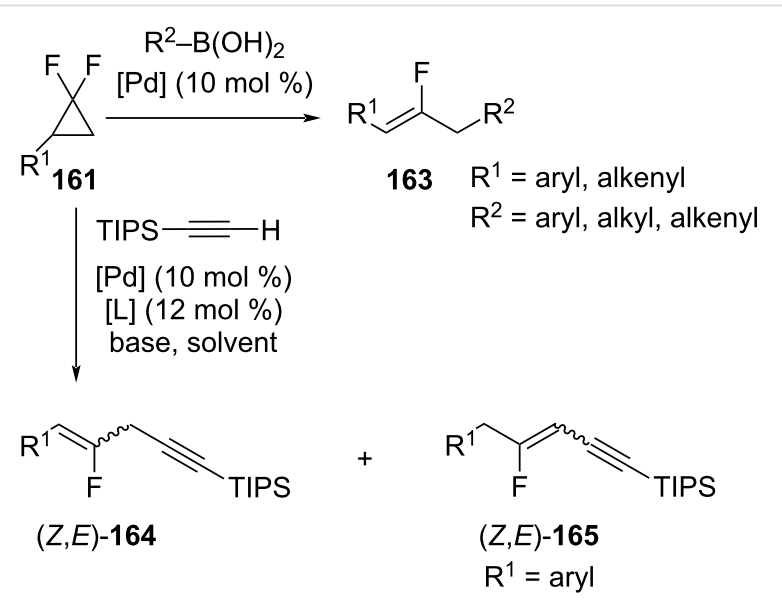

Scheme 70: Pd-catalyzed cross-coupling reactions of gem-difluorinated cyclopropanes 161 .

Shortly before, a Pd-catalyzed ring-opening sulfonylation of gem-difluorocyclopropanes with the formation of 2-fluoroallylic sulfones 166 has been reported (Scheme 71) [122]. The reaction of 2-(2,2-difluorocyclopropyl)naphthalene (167) with sodium arylsulfinates 168 under palladium catalysis afforded the 2-fluoroallylic sulfones $\mathbf{1 6 6}$ in moderate to good yields with
(Z)-selectivity. This method showed a good compatibility with a broad range of substrates and substituents.

As highlighted by these pioneering works [119-122], the direct Pd-catalyzed transformation of gem-difluorocyclopropanes to monofluoroalkenes is a promising approach towards the synthesis of fluorinated alkenes.

As is evident from the examples presented above, the ring opening of gem-difluorocyclopropanes occurs quite commonly under a variety of mild reaction conditions that are compatible with the presence of additional functionalities. The main reason for the ring opening is its inherent strain, with bond angles close to $60^{\circ}$ instead of $109^{\circ}$ that is normal for $\mathrm{sp}^{3}$ hybridized carbon atoms. The mechanisms of the ring opening that are favored in particular examples are determined by the additional substituents present on the cyclopropane ring, as well as the choice of reagents, catalysts, and conditions. The carbon atom 1 of the 1,1-difluorocyclopropane system, being attached directly to the fluorine atoms, has a significant partial positive charge and can be a site for nucleophilic attack. The neighboring carbon atoms also possess partial positive charges, albeit less pronounced. The combination of ring strain and the deficit of the electronic density leads to the possibility of ring opening by nucleophiles. As is the case for the nucleophilic opening of epoxides, the regiochemistry of this process is often controlled very effectively by the combined steric and electronic effects of the substituents attached to the ring, with a spectrum of $S_{N} 1$ and $S_{N} 2$ like reactivity possible.

Several different types of catalysts have proved effective in facilitating the ring opening of difluorocyclopropane derivatives. Lewis acids (e.g., group 13 halides and silver ions) can polarize carbonyl substituents and assist the loss of halide ions, leading to the formation of carbocation intermediates. Lowvalent transition metals such as $\operatorname{Pd}(0)$ also have a valuable catalytic role, particularly because of their ability to participate in oxidative addition reactions and to form $\pi$-allyl complexes.

In the absence of nucleophiles, homolysis of the distal $\mathrm{C}-\mathrm{C}$ bond takes place under the effect of high temperature. Such

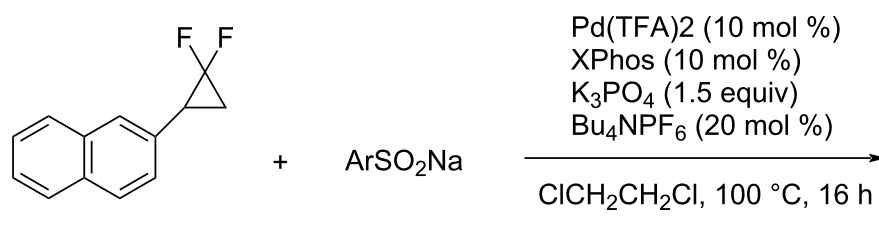

167

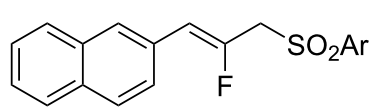

$55-79 \%$

Scheme 71: The (Z)-selective Pd-catalyzed ring-opening sulfonylation of 2-(2,2-difluorocyclopropyl)naphthalene (167). 
selectivity is caused by the possibility of the resonance stabilization of the biradical that is formed. If other reagents are absent, the biradical can rearrange and recombine, leading to isomerization of the starting material as was observed in the case of 1,1-difluoro-2,3-dialkylcyclopropanes. Further applications of free radical chemistry have developed through the use of radical initiators under comparatively mild conditions to form cyclopropylmethyl radicals, which can readily release their strain by opening to give homoallyl radicals.

$\mathrm{gem}$-Difluorocyclopropanes, because of their ability to participate in such a diverse collection of ring-opening reactions and act as precursors for multifunctional products, both with and without fluorine, can play an exceptional role as intermediates for organic synthesis.

\section{Biological activity of difluorocyclopropane derivatives}

A further reason of interest in gem-difluorocyclopropanes stems from the unique influence of the fluorine substituents not only on the physicochemical properties, but also on the biological properties. Approximately one quarter of medicinal preparations, such as antibiotics, anticancer, and antimycotic preparations, contain at least one fluorine atom in their structure. The cyclopropane ring is a particularly attractive scaffold for incorporation in the design of pharmaceuticals because of its compactness, conformational rigidity, and the ability to support substituents in well-defined regions of three-dimensional space.

There is a high risk of failure of cancer chemotherapy due to the development of multidrug resistance which can arise by an overexpression of P-glycoprotein, an energy-dependent drug efflux pump. In this case increased dosages of therapeutics are required, leading to dangerous toxicity and high risk of death Therefore, modulators have been developed in order to restore the sensitivity to chemotherapy. One such modulator is the gemdifluorocyclopropane derivative LY335979.3 HCl (zosuquidar hydrochloride, Figure 1) [123].

PF-06700841 (Figure 1) is a dual protein kinase inhibitor that targets cytokine signaling pathways associated with autoimmune disorders such as plaque psoriasis [124,125]. The noncovalent binding between this inhibitor and the target proteins has been characterized by single crystal X-ray diffraction; the difluoromethylene unit was found to project into the phosphatebinding loops of the kinases' ATP binding sites.

Another use of gem-difluorocyclopropanes has been in the preparation of nucleoside analogs, which can act as chemotherapeutic agents. Carbocyclic nucleosides can have antiviral activity. Therefore, Csuk and Eversmann [32] studied the synthesis of

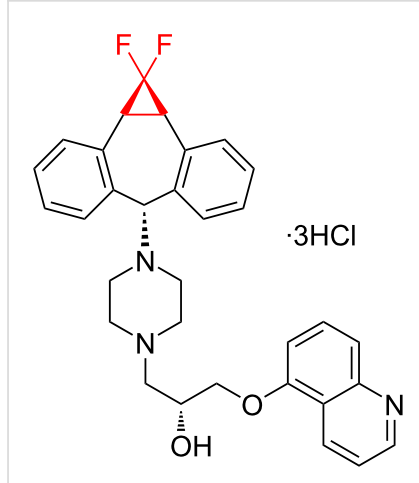

zosuquidar hydrochloride<smiles>Cn1cc(Nc2nccc(N3CC4CCC(C3)N4C(=O)[C@@H]3CC3(F)F)n2)cn1</smiles>

PF-06700841

Figure 1: Structures of zosuquidar hydrochloride and PF-06700841.

gem-difluorocyclopropyl carbocyclic nucleosides for use against HIV.

Furthermore, Wang et al. reported the biological activity of the methylene-gem-difluorocyclopropane analogs of nucleosides 169a, 169b, 170a, and 170b that were obtained from methylene-gem-difluorocyclopropane 74 (Scheme 72) [76]. Compound 169a was active against human cytomegalovirus (HCMV) in human foreskin fibroblast cells. Both compounds 169a and 170a had antitumor activity, but derivative 169a was found to be more selective in comparison to its isomer 170a.

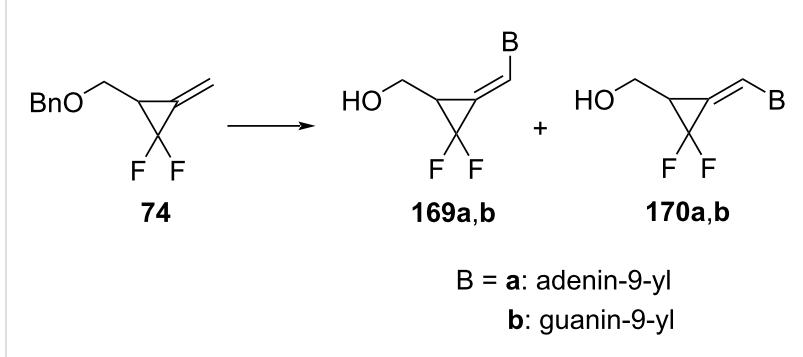

Scheme 72: Synthesis of methylene-gem-difluorocyclopropane analogs of nucleosides.

Recently, there has been much interest in the synthesis of organic compounds that can cleave DNA following photoirradiation. Ninomiya et al. described anthracene-difluorocyclopropane hybrids, which were modified in order to maximize DNA cleavage [126]. DNA damage was induced due to the radical decomposition of the cyclopropane ring. The active derivatives included compounds $(S, S)$-171, $(S, S)$-172, and $(R, R)$ 172 (Figure 2).

Further examples highlighting the importance of gem-difluorocyclopropanes in modern drug discovery are shown in Figure 3. Compound $\mathbf{1 7 3}$ was selected as a selective agonist for the 


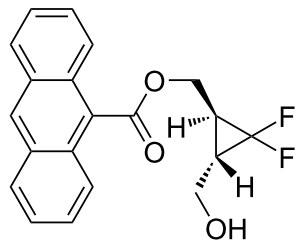

alcohol $(S, S)-171$

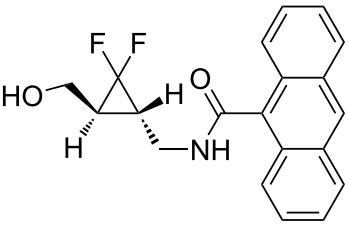

amide $(S, S)-172$

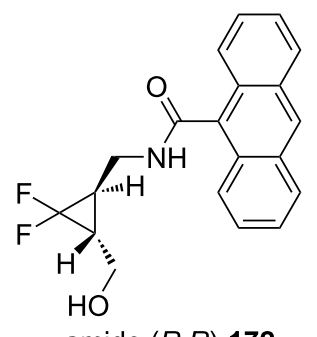

amide $(R, R)-172$

Figure 2: Anthracene-difluorocyclopropane hybrid derivatives.<smiles>NC(C(=O)O)C(C(=O)O)C(F)(F)F</smiles>

173 (L-F2CCG-I inhibitor)<smiles>O=C(c1cnc2[nH]ncc2c1)N1CCC2(CC1)CN1C3CC(F)(F)CN3C(=O)CN1C2=O</smiles>

174 DDR 1 inhibitor<smiles>COC[C@H](NC(=O)Nc1cc2[nH]nc(C3CC3(F)F)c2cn1)c1ccc(F)cc1</smiles>

175 (ERK-2 inhibitor, $\left.\mathrm{IC}_{50}=3.6 \mathrm{nM}\right)$<smiles>COC1(c2ccc(F)cc2)CCC(Oc2cc[n+]3c(C4CC4(F)F)n[nH]c3c2C(F)(F)F)CC1</smiles>

176 (mGluR2 agonist, $\mathrm{EC}_{50}=6.9 \mathrm{~nm}$ )<smiles>CC(C)C(=O)Nc1cnn(C2CC2(F)F)c1-c1ccnc([C@@H](CCC[C@@H](C)C2CC2)N2CCC(c3cc(Cl)ccc3-n3cc(Cl)nn3)=CC2=O)c1</smiles>

177 (FXla inhibitor, $K_{1}=0.36 \mathrm{nM}$ )

Figure 3: Further examples of difluorcyclopropanes in modern drug discovery.

metabotropic glutamate receptor 2 with antiepileptogenic effects [127]. Compound $\mathbf{1 7 4}$ is a discoidin domain receptor 1 inhibitor with the potential of being applied for the treatment of cancer and inflammation related disorders [128]. Compound 175 is an extracellular signal-regulated kinase 2 inhibitor with potential as an anticancer drug [129]. Compound 176 has potential for the treatment of neurological and psychiatric disorders [130] and compound $\mathbf{1 7 7}$ is an FXIa inhibitor with anticoagulant activity [131].

Another reason for the great interest in difluorocyclopropane derivatives arises also from the compounds' ability to control the plant growth and fruit ripening. Ethylene is a plant hormone, which controls fruit ripening [132], seed germination, and leaf senescence. It is biosynthesized from 1-aminocyclopropane-1carboxylic acid (ACC) and under stress conditions, ethylene can be produced in excess amounts, leading to senescence, chlorosis, and abscission. The ACC analog 1-amino-2,2-difluorocyclopropane-1-carboxylic acid can inhibit the enzyme ACC deaminase, which stops fruits from ripening, prevents the loss of leaves, etc. With the help of this substance, the shelf life of vegetables and fruits can be increased.

In addition, gem-difluorocyclopropanes can be used in agriculture against spider mite (Tetrahychus urticae), diamondback moth (Plutella xylostella), worm (Spodoptera littoralis) and Mexican caryopsis (Epilachna varivestis) [133].

\section{Conclusion}

gem-Difluorocyclopropanes were discovered to be effective substrates for the generation of medicinal and bioactive materials. Lately, more studies have been made regarding the inclusion of this motif into drug structures. The presence of the geminal fluorine atoms was associated with the increase of the lipophilicity, bioavailability, metabolic stability, and the binding affinity of biologically active materials. For instance, gem-difluorocyclopropanes have been incorporated into nucleoside analogs, which act as antiviral agents and where one of the 
roles of the fluorine is to act as a hydrogen-bond acceptor. Antimicrobial agents, amino acids, and drugs used for the control of chemotherapy sensitivity also include difluorocyclopropane derivatives.

Therefore, the synthesis of difluorocyclopropanes on a large scale and in safe conditions is a subject of great importance and relevance. This review considered numerous preparation methods for gem-difluorocyclopropanes. However, the most popular approach is based on the use of the reactive intermediate difluorocarbene, which can participate in stereospecific $[2+1]$-cycloadditions with alkenes. Difluorocarbene addition reactions have been complemented by other synthetic methods, some of which have provided optically active difluorocyclopropanes, e.g., by functional group interconversions involving enzyme-catalyzed esterifications and catalytic asymmetric hydrogenation reactions of difluorocylopropenes.

Thermal rearrangements and ring-opening reactions place difluorocyclopropanes at the crossroads in the synthesis of useful compounds. These processes often lead to the cleavage of the distal $\mathrm{C}-\mathrm{C}$ bond and the cleavage of the proximal bond has also been observed but the electronic and steric factors determining the regioselectivity are now well appreciated.

Recent strategies including the transition metal-catalyzed transformations of highly substituted difluorocyclopropanes opened the door for the development of asymmetric approaches with the use of chiral ligands and chiral reagents. This is of great importance for the discovery and the development of new bioactive compounds. There have been made many discoveries regarding the synthesis and reactivity of difluorocyclopropanes in the last 60 years. However, more work is needed to develop catalytic enantioselective processes, both, for the cyclopropane ring formation and ring opening. These compounds have yet to receive the attention that has provided effective methods for the catalytic asymmetric transformations involving other threemembered rings, such as epoxidation, Simmons-Smith cyclopropanation, and epoxide opening. The possibility of using complexes of abundant transition metals such as copper as reagents for difluorocarbene transfer [90] raises our hopes for future developments in this area.

\section{ORCID ${ }^{\circledR}$ iDs}

Sergazy M. Adekenov - https://orcid.org/0000-0001-7588-6174

\section{References}

1. Itoh, T. gem-Difluorinated cyclopropanes as key building blocks for novel biologically active molecules. In Fluorine in Bioorganic and Medicinal Chemistry; Ojima, I., Ed.; Wiley-Blackwell: Chichester, UK, 2009; pp 313-334. doi:10.1002/9781444312096.ch12
2. Song, X.; Xu, C.; Wang, M. Tetrahedron Lett. 2017, 58, 1806-1816. doi:10.1016/j.tetlet.2017.03.058

3. Welch, J. T. Applications of pentafluorosulfanyl substitution in life science research. In Fluorine in pharmaceutical and medicinal chemistry: from biophysical aspects to clinical applications; Gouverneur, V.; Muller, K., Eds.; Imperial College Press: London, U.K., 2012; pp 175-208. doi:10.1142/9781848166363_0006

4. Huchet, Q. A.; Kuhn, B.; Wagner, B.; Kratochwil, N. A.; Fischer, H.; Kansy, M.; Zimmerli, D.; Carreira, E. M.; Müller, K. J. Med. Chem. 2015, 58, 9041-9060. doi:10.1021/acs.jmedchem.5b01455

5. Zhou, Y.; Wang, J.; Gu, Z.; Wang, S.; Zhu, W.; Aceña, J. L.; Soloshonok, V. A.; Izawa, K.; Liu, H. Chem. Rev. 2016, 116, 422-518. doi:10.1021/acs.chemrev.5b00392

6. Brahms, D. L. S.; Dailey, W. P. Chem. Rev. 1996, 96, 1585-1632. doi:10.1021/cr941141k

7. Dolbier, W. R., Jr.; Battiste, M. A. Chem. Rev. 2003, 103, 1071-1098. doi:10.1021/cr010023b

8. Fedoryński, M. Chem. Rev. 2003, 103, 1099-1132. doi:10.1021/cr0100087

9. Atkinson, B. J. Chem. Soc. 1952, 2684-2694. doi:10.1039/jr9520002684

10. Tarrant, P.; Lovelace, A. M.; Lilyquist, M. R. J. Am. Chem. Soc. 1955, 77, 2783-2787. doi:10.1021/ja01615a033

11. Misani, F.; Speers, L.; Lyon, A. M. J. Am. Chem. Soc. 1956, 78, 2801-2804. doi:10.1021/ja01593a041

12. von E. Doering, W.; Hoffmann, A. K. J. Am. Chem. Soc. 1954, 76, 6162-6165. doi:10.1021/ja01652a087

13. Tian, F.; Kruger, V.; Bautista, O.; Duan, J.-X.; Li, A.-R.; Dolbier, W. R., Jr.; Chen, Q.-Y. Org. Lett. 2000, 2, 563-564. doi:10.1021/ol0055622

14. Hine, J.; Langford, P. B. J. Am. Chem. Soc. 1957, 79, 5497-5500. doi:10.1021/ja01577a046

15. Hine, J.; Porter, J. J. J. Am. Chem. Soc. 1957, 79, 5493-5496. doi:10.1021/ja01577a045

16. Feast, W. J.; Gimeno, M.; Kenwright, A. M. Macromolecules 2006, 39 4076-4080. doi:10.1021/ma0527348

17. Volchkov, N. V.; Lipkind, M. B.; Nefedov, O. M. Russ. Chem. Bull. 2019, 68, 1232-1238. doi:10.1007/s11172-019-2546-8

18. Dolbier, W. R., Jr.; Wojtowicz, H.; Burkholder, C. R. J. Org. Chem. 1990, 55, 5420-5422. doi:10.1021/jo00306a027

19. Burton, D. J.; Naae, D. G. J. Am. Chem. Soc. 1973, 95, 8467-8468. doi:10.1021/ja00806a055

20. Bessard, Y.; Müller, U.; Schlosser, M. Tetrahedron 1990, 46, 5213-5221. doi:10.1016/s0040-4020(01)87828-5

21. Bałcerzak, P.; Fedoryński, M.; Jończyk, A. J. Chem. Soc., Chem. Commun. 1991, 826-827. doi:10.1039/c39910000826

22. Grudzień, K.; Basak, T.; Barbasiewicz, M.; Wojciechowski, T. M.; Fedoryński, M. J. Fluorine Chem. 2017, 197, 106-110. doi:10.1016/j.jfluchem.2017.03.014

23. Birchall, J. M.; Cross, G. E.; Haszeldine, R. N. Proc. Chem. Soc., London 1960, 81.

24. Shibuya, A.; Okada, M.; Nakamura, Y.; Kibashi, M.; Horikawa, H.; Taguchi, T. Tetrahedron 1999, 55, 10325-10340. doi:10.1016/s0040-4020(99)00588-8

25. Thomas, M. G.; Suckling, C. J.; Pitt, A. R.; Suckling, K. E. J. Chem. Soc., Perkin Trans. 1 1999, 3191-3198. doi:10.1039/a904826j

26. Kubyshkin, V.; Kheylik, Y.; Mykhailiuk, P. K. J. Fluorine Chem. 2015, 175, 73-83. doi:10.1016/j.jfluchem.2015.03.008 
27. Fujioka, Y.; Amii, H. Org. Lett. 2008, 10, 769-772. doi:10.1021/ol702851t

28. Lee, C.-C.; Lin, S.-T.; Ke, S.-Y. Tetrahedron 2007, 63, 120-125. doi:10.1016/j.tet.2006.10.041

29. Oshiro, K.; Morimoto, Y.; Amii, H. Synthesis 2010, 2080-2084. doi:10.1055/s-0029-1218754

30. Kageshima, Y.; Suzuki, C.; Oshiro, K.; Amii, H. Synlett 2015, 26, 63-66. doi:10.1055/s-0034-1379599

31. Gill, D. M.; McLay, N.; Waring, M. J.; Wilkinson, C. T.; Sweeney, J. B. Synlett 2014, 25, 1756-1758. doi:10.1055/s-0033-1341155

32. Csuk, R.; Eversmann, L. Tetrahedron 1998, 54, 6445-6456. doi:10.1016/s0040-4020(98)00324-X

33. Zheng, J.; Cai, J.; Lin, J.-H.; Guo, Y.; Xiao, J.-C. Chem. Commun. 2013, 49, 7513-7515. doi:10.1039/c3cc44271c

34. Zheng, J.; Lin, J.-H.; Cai, J.; Xiao, J.-C. Chem. - Eur. J. 2013, 19, 15261-15266. doi:10.1002/chem.201303248

35. Dolbier, W. R., Jr.; Tian, F.; Duan, J.-X.; Li, A.-R.; Ait-Mohand, S.; Bautista, O.; Buathong, S.; Marshall Baker, J.; Crawford, J.; Anselme, P.; Cai, X. H.; Modzelewska, A.; Koroniak, H.; Battiste, M. A.; Chen, Q.-Y. J. Fluorine Chem. 2004, 125, 459-469. doi:10.1016/j.jfluchem.2003.12.002

36. Hang, X.-C.; Gu, W.-P.; Chen, Q.-Y.; Xiao, J.-C. Tetrahedron 2009, 65, 6320-6324. doi:10.1016/j.tet.2009.06.019

37. Fuchibe, K.; Takayama, R.; Yokoyama, T.; Ichikawa, J. Chem. - Eur. J. 2017, 23, 2831-2838. doi:10.1002/chem.201604578

38. Eusterwiemann, S.; Martinez, H.; Dolbier, W. R., Jr. J. Org. Chem. 2012, 77, 5461-5464. doi:10.1021/jo300876z

39. Wang, F.; Luo, T.; Hu, J.; Wang, Y.; Krishnan, H. S.; Jog, P. V.; Ganesh, S. K.; Prakash, G. K. S.; Olah, G. A. Angew. Chem., Int. Ed. 2011, 50, 7153-7157. doi:10.1002/anie.201101691

40. Rullière, P.; Cyr, P.; Charette, A. B. Org. Lett. 2016, 18, 1988-1991. doi:10.1021/acs.orglett.6b00573

41. Thomson, C. J.; Zhang, Q.; Al-Maharik, N.; Bühl, M.; Cordes, D. B.; Slawin, A. M. Z.; O'Hagan, D. Chem. Commun. 2018, 54, 8415-8418. doi:10.1039/c8cc04964e

42. Burch, J. D.; Barrett, K.; Chen, Y.; DeVoss, J.; Eigenbrot, C.; Goldsmith, R.; Ismaili, M. H. A.; Lau, K.; Lin, Z.; Ortwine, D. F.; Zarrin, A. A.; McEwan, P. A.; Barker, J. J.; Ellebrandt, C.; Kordt, D.; Stein, D. B.; Wang, X.; Chen, Y.; Hu, B.; Xu, X.; Yuen, P.-W.; Zhang, Y.; Pei, Z. J. Med. Chem. 2015, 58, 3806-3816. doi:10.1021/jm501998m

43. Zhou, J.; Campbell-Conroy, E. L.; Silina, A.; Uy, J.; Pierre, F.; Hurley, D. J.; Hilgraf, N.; Frieman, B. A.; DeNinno, M. P. J. Org. Chem. 2015, 80, 70-79. doi:10.1021/j0501967m

44. Hryshchuk, O. V.; Varenyk, A. O.; Yurov, Y.; Kuchkovska, Y. O.; Tymtsunik, A. V.; Grygorenko, O. O. Eur. J. Org. Chem. 2020, 2217-2224. doi:10.1002/ejoc.202000346

45. Fang, Z.; Al-Maharik, N.; Kirsch, P.; Bremer, M.; Slawin, A. M. Z.; O'Hagan, D. Beilstein J. Org. Chem. 2020, 16, 674-680. doi:10.3762/bjoc. 16.65

46. Bychek, R. M.; Levterov, V. V.; Sadkova, I. V.; Tolmachev, A. A.; Mykhailiuk, P. K. Chem. - Eur. J. 2018, 24, 12291-12297. doi:10.1002/chem.201705708

47. Nicolaou, K. C.; Shelke, Y. G.; Dherange, B. D.; Kempema, A.; Lin, B.; Gu, C.; Sandoval, J.; Hammond, M.; Aujay, M.; Gavrilyuk, J. J. Org. Chem. 2020, 85, 2865-2917. doi:10.1021/acs.joc.0c00123

48. Wang, F.; Zhang, W.; Zhu, J.; Li, H.; Huang, K.-W.; Hu, J. Chem. Commun. 2011, 47, 2411-2413. doi:10.1039/c0cc04548a

49. Li, L.; Wang, F.; Ni, C.; Hu, J. Angew. Chem., Int. Ed. 2013, 52, 12390-12394. doi:10.1002/anie.201306703
50. Brauer, D. J.; Bürger, H.; Buchheim-Spiegel, S.; Pawelke, G. Eur. J. Inorg. Chem. 1999, 255-261. doi:10.1002/(sici)1099-0682(19990202)1999:2<255::aid-ejic255>3.0.c $0 ; 2-f$

51. Birchall, J. M.; Haszeldine, R. N.; Roberts, D. W. J. Chem. Soc., Perkin Trans. 1 1973, 1071-1078. doi:10.1039/p19730001071

52. Mahler, W.; Resnick, P. R. J. Fluorine Chem. 1974, 3, 451-452. doi:10.1016/s0022-1139(00)82650-0

53. Volchkov, N. V.; Lipkind, M. B.; Novikov, M. A.; Nefedov, O. M. Russ. Chem. Bull. 2015, 64, 658-663. doi:10.1007/s11172-015-0914-6

54. Moss, R. A.; Wang, L.; Krogh-Jespersen, K. J. Am. Chem. Soc. 2009, 131, 2128-2130. doi:10.1021/ja809370j

55. Mitsch, R. A. J. Am. Chem. Soc. 1965, 87, 758-761. doi:10.1021/ja01082a015

56. Seyferth, D.; Hopper, S. P. J. Org. Chem. 1972, 37, 4070-4075. doi:10.1021/jo00798a020

57. Nowak, I.; Cannon, J. F.; Robins, M. J. Org. Lett. 2004, 6, 4767-4770. doi:10.1021/ol047943b

58. Tandon, M.; Singh, S.; Xu, L.; Kumar, P.; Wiebe, L. I.; Knaus, E. E.; Gati, W. P.; Tempest, M. L. Drug Des. Discovery 1992, 9, 79-91.

59. Clark, H. C.; Willis, C. J. J. Am. Chem. Soc. 1960, 82, 1888-1891. doi:10.1021/ja01493a014

60. Seyferth, D.; Dertouzos, H.; Suzuki, R.; Mui, J. Y. P. J. Org. Chem. 1967, 32, 2980-2984. doi:10.1021/jo01285a011

61. Krause, L. J.; Morrison, J. A. J. Am. Chem. Soc. 1981, 103, 2995-3001. doi:10.1021/ja00401a015

62. Eujen, R.; Hoge, B. J. Organomet. Chem. 1995, 503, C51-C54. doi:10.1016/0022-328x(95)05848-j

63. Kirii, N. V.; Pazenok, S. V.; Yagupolskii, Y. L.; Naumann, D.; Turra, W. Russ. J. Org. Chem. 2001, 37, 207-209. doi:10.1023/a:1012318710556

64. Aikawa, K.; Toya, W.; Nakamura, Y.; Mikami, K. Org. Lett. 2015, 17, 4996-4999. doi:10.1021/acs.orglett.5b02439

65. Nakamura, Y.; Fujiu, M.; Murase, T.; Itoh, Y.; Serizawa, H.; Aikawa, K.; Mikami, K. Beilstein J. Org. Chem. 2013, 9, 2404-2409. doi:10.3762/bjoc.9.277

66. Aikawa, K.; Nakamura, Y.; Yokota, Y.; Toya, W.; Mikami, K. Chem. - Eur. J. 2015, 21, 96-100. doi:10.1002/chem.201405677

67. Tskhovrebov, A. G.; Lingnau, J. B.; Fürstner, A. Angew. Chem., Int. Ed. 2019, 58, 8834-8838. doi:10.1002/anie.201903957

68. Taguchi, T.; Okada, M. J. Fluorine Chem. 2000, 105, 279-283. doi:10.1016/s0022-1139(99)00272-9

69. Kagabu, S.; Ando, C.; Ando, J. J. Chem. Soc., Perkin Trans. 1 1994, 739-751. doi:10.1039/p19940000739

70. Lee, C.-C.; Lin, S.-T. Synthesis 2000, 496-498. doi:10.1055/s-2000-6358

71. Tian, H.; Shimakoshi, H.; Imamura, K.; Shiota, Y.; Yoshizawa, K.; Hisaeda, Y. Chem. Commun. 2017, 53, 9478-9481. doi:10.1039/c7cc04377e

72. Itoh, T.; Ishida, N.; Ohashi, M.; Asep, R.; Nohira, H. Chem. Lett. 2003, 32, 494-495. doi:10.1246/cl.2003.494

73. Yamani, K.; Pierre, H.; Archambeau, A.; Meyer, C.; Cossy, J. Angew. Chem., Int. Ed. 2020, 59, 18505-18509. doi:10.1002/anie.202008572

74. Gassen, K. R.; Baasner, B. J. Fluorine Chem. 1990, 49, 127-139. doi:10.1016/s0022-1139(00)80369-3 
75. Taguchi, T.; Kurishita, M.; Shibuya, A.; Aso, K. Tetrahedron 1997, 53, 9497-9508. doi:10.1016/s0040-4020(97)00613-3

76. Wang, R.; Ksebati, M. B.; Corbett, T. H.; Kern, E. R.; Drach, J. C.; Zemlicka, J. J. Med. Chem. 2001, 44, 4019-4022. doi:10.1021/jm010191w

77. Wang, M.-X.; Feng, G.-Q.; Zheng, Q.-Y. Tetrahedron: Asymmetry 2004, 15, 347-354. doi:10.1016/j.tetasy.2003.11.016

78. Yang, Q.; Sheng, M.; Li, X.; Tucker, C.; Vásquez Céspedes, S.; Webb, N. J.; Whiteker, G. T.; Yu, J. Org. Process Res. Dev. 2020, 24, 916-939. doi:10.1021/acs.oprd.0c00159

79. Sekine, K.; Ushiyama, A.; Endo, Y.; Mikami, K. J. Org. Chem. 2020, 85, 7916-7924. doi:10.1021/acs.joc.0c00622

80. Itoh, T.; Mitsukura, K.; Furutani, M. Chem. Lett. 1998, 27, 903-904. doi:10.1246/cl.1998.903

81. Kirihara, M.; Kawasaki, M.; Takuwa, T.; Kakuda, H.; Wakikawa, T.; Takeuchi, Y.; Kirk, K. L. Tetrahedron: Asymmetry 2003, 14 1753-1761. doi:10.1016/s0957-4166(03)00350-1

82. Ferrero, J. C.; De Staricco, E. A. R.; Staricco, E. H. J. Phys. Chem. 1975, 79, 1242-1246. doi:10.1021/j100580a002

83. Jefford, C. W.; Mareda, J.; Gehret, J. C. E.; Kabengele, T.; Graham, W. D.; Burger, U. J. Am. Chem. Soc. 1976, 98, 2585-2593. doi:10.1021/ja00425a030

84. Dolbier, W. R., Jr. Acc. Chem. Res. 1981, 14, 195-200. doi:10.1021/ar00067a001

85. Getty, S. J.; Hrovat, D. A.; Xu, J. D.; Barker, S. A.; Borden, W. T. J. Chem. Soc., Faraday Trans. 1994, 90, 1689-1701. doi:10.1039/ft9949001689

86. Tian, F.; Lewis, S. B.; Bartberger, M. D.; Dolbier, W. R., Jr.; Borden, W. T. J. Am. Chem. Soc. 1998, 120, 6187-6188. doi:10.1021/ja980969b

87. O'Neal, H. E.; Benson, S. W. J. Phys. Chem. 1968, 72, 1866-1887. doi:10.1021/j100852a003

88. Dolbier, W. R., Jr.; Sellers, S. F. J. Am. Chem. Soc. 1982, 104, 2494-2497. doi:10.1021/ja00373a026

89. Orr, D.; Percy, J. M.; Tuttle, T.; Kennedy, A. R.; Harrison, Z. A. Chem. - Eur. J. 2014, 20, 14305-14316. doi:10.1002/chem.201403737

90. Fuchibe, K.; Takayama, R.; Aono, T.; Hu, J.; Hidano, T.; Sasagawa, H.; Fujiwara, M.; Miyazaki, S.; Nadano, R.; Ichikawa, J. Synthesis 2018, 50, 514-528. doi:10.1055/s-0036-1591728

91. Tian, F.; Bartberger, M. D.; Dolbier, W. R., Jr. J. Org. Chem. 1999, 64, 540-546. doi:10.1021/j0981594f

92. Dolbier, W. R., Jr.; Gautriaud, E.; Cai, X. J. Fluorine Chem. 2005, 126, 339-343. doi:10.1016/j.jluchem.2004.12.004

93. Hang, X.-C.; Gu, W.-P.; Chen, Q.-Y.; Xiao, J.-C.; Xu, W.-G.; Liu, S. J. Fluorine Chem. 2011, 132, 63-67. doi:10.1016/j.jluchem.2010.11.007

94. Gajewski, J. J. J. Am. Chem. Soc. 1970, 92, 3688-3696. doi:10.1021/ja00715a025

95. Dolbier, W. R., Jr.; Sellers, S. F.; Al-Sader, B. H.; Elsheimer, S. J. Am. Chem. Soc. 1981, 103, 715-717. doi:10.1021/ja00393a059

96. Battiste, M. A.; Tian, F.; Baker, J. M.; Bautista, O.; Villalobos, J.; Dolbier, W. R., Jr. J. Fluorine Chem. 2003, 119, 39-51. doi:10.1016/s0022-1139(02)00248-8

97. Kobayashi, Y.; Taguchi, T.; Morikawa, T.; Takase, T.; Takanashi, H. Tetrahedron Lett. 1980, 21, 1047-1050. doi:10.1016/s0040-4039(00)78835-6

98. Kobayashi, Y.; Taguchi, T.; Morikawa, T.; Takase, T.; Takanashi, H. J. Org. Chem. 1982, 47, 3232-3236. doi:10.1021/j000138a006
99. Xu, W.; Chen, Q.-Y. Org. Biomol. Chem. 2003, 1, 1151-1156. doi:10.1039/b212232d

100.Sugiishi, T.; Matsumura, C.; Amii, H. Org. Biomol. Chem. 2020, 18, 3459-3462. doi:10.1039/c9ob02713k

101.Xu, W.; Dolbier, W. R., Jr.; Salazar, J. J. Org. Chem. 2008, 73, 3535-3538. doi:10.1021/j0800337t

102.Xu, W.; Ghiviriga, I.; Chen, Q.-Y.; Dolbier, W. R., Jr. J. Fluorine Chem. 2010, 131, 958-963. doi:10.1016/j.jluchem.2010.06.021

103. Nihei, T.; Hoshino, T.; Konno, T. Org. Lett. 2014, 16, 4170-4173. doi:10.1021/ol5018596

104. Morikawa, T.; Uejima, M.; Yoda, K.; Taguchi, T. Chem. Lett. 1990, 19, 467-468. doi:10.1246/cl.1990.467

105. Munemori, D.; Narita, K.; Nokami, T.; Itoh, T. Org. Lett. 2014, 16, 2638-2641. doi:10.1021/ol500803r

106. Masuhara, Y.; Tanaka, T.; Takenaka, H.; Hayase, S.; Nokami, T.; Itoh, T. J. Org. Chem. 2019, 84, 5440-5449. doi:10.1021/acs.joc.9b00415

107.Takenaka, H.; Masuhara, Y.; Narita, K.; Nokami, T.; Itoh, T. Org. Biomol. Chem. 2018, 16, 6106-6114. doi:10.1039/c8ob01740a

108. Goto, T.; Kawasaki-Takasuka, T.; Yamazaki, T. J. Org. Chem. 2019, 84, 9509-9518. doi:10.1021/acs.joc.9b01078

109. Specklin, S.; Fenneteau, J.; Subramanian, P.; Cossy, J. Chem. - Eur. J. 2018, 24, 332-336. doi:10.1002/chem.201704956

110.Hang, X.-C.; Chen, Q.-Y.; Xiao, J.-C. J. Org. Chem. 2008, 73, 8598-8600. doi:10.1021/j0801610t

111. Hang, X.-C.; Chen, Q.-Y.; Xiao, J.-C. J. Org. Chem. 2011, 76, 2384 doi:10.1021/jo200328n

112.Cheng, Z.-L.; Xiao, J.-C.; Liu, C.; Chen, Q.-Y. Eur. J. Org. Chem. 2006, 5581-5587. doi:10.1002/ejoc.200600616

113.Yang, T.-P.; Lin, J.-H.; Chen, Q.-Y.; Xiao, J.-C. Chem. Commun. 2013, 49, 9833-9835. doi:10.1039/c3cc45456h

114.Yang, T.-P.; Li, Q.; Lin, J.-H.; Xiao, J.-C. Chem. Commun. 2014, 50 , 1077-1079. doi:10.1039/c3cc47879c

115.Dolbier, W. R., Jr.; Cornett, E.; Martinez, H.; Xu, W. J. Org. Chem. 2011, 76, 3450-3456. doi:10.1021/j0200423y

116. Isogai, K.; Nishizawa, N.; Saito, T.; Sakai, J.-i. Bull. Chem. Soc. Jpn. 1983, 56, 1555-1556. doi:10.1246/bcsj.56.1555

117.Wenz, J.; Rettenmeier, C. A.; Wadepohl, H.; Gade, L. H. Chem. Commun. 2016, 52, 202-205. doi:10.1039/c5cc08950f

118.Song, X.; Xu, C.; Du, D.; Zhao, Z.; Zhu, D.; Wang, M. Org. Lett. 2017, 19, 6542-6545. doi:10.1021/acs.orglett.7b03254

119.Xu, J.; Ahmed, E.-A.; Xiao, B.; Lu, Q.-Q.; Wang, Y.-L.; Yu, C.-G.; Fu, Y. Angew. Chem., Int. Ed. 2015, 54, 8231-8235. doi:10.1002/anie.201502308

120. Ahmed, E.-A. M. A.; Suliman, A. M. Y.; Gong, T.-J.; Fu, Y. Org. Lett. 2019, 21, 5645-5649. doi:10.1021/acs.orglett.9b01979

121. Ahmed, E.-A. M. A.; Suliman, A. M. Y.; Gong, T.-J.; Fu, Y. Org. Lett. 2020, 22, 1414-1419. doi:10.1021/acs.orglett.0c00022

122. Ni, J.; Nishonov, B.; Pardaev, A.; Zhang, A. J. Org. Chem. 2019, 84, 13646-13654. doi:10.1021/acs.joc.9b01897

123. Barnett, C. J.; Huff, B.; Kobierski, M. E.; Letourneau, M.; Wilson, T. M. J. Org. Chem. 2004, 69, 7653-7660. doi:10.1021/jo049051v

124. Fensome, A.; Ambler, C. M.; Arnold, E.; Banker, M. E.; Brown, M. F.; Chrencik, J.; Clark, J. D.; Dowty, M. E.; Efremov, I. V.; Flick, A.; Gerstenberger, B. S.; Gopalsamy, A.; Hayward, M. M.; Hegen, M.; Hollingshead, B. D.; Jussif, J.; Knafels, J. D.; Limburg, D. C.; Lin, D.; Lin, T. H.; Pierce, B. S.; Saiah, E.; Sharma, R.; Symanowicz, P. T.; Telliez, J.-B.; Trujillo, J. I.; Vajdos, F. F.; Vincent, F.; Wan, Z.-K.; Xing, L.; Yang, X.; Yang, X.; Zhang, L. J. Med. Chem. 2018, 61, 8597-8612. doi:10.1021/acs.jmedchem.8b00917 
125. Forman, S. B.; Pariser, D. M.; Poulin, Y.; Vincent, M. S.; Gilbert, S. A.; Kieras, E. M.; Qiu, R.; Yu, D.; Papacharalambous, J.; Tehlirian, C.; Peeva, E. J. Invest. Dermatol. 2020, 140, 2359-2370.e5. doi:10.1016/j.jid.2020.03.962

126. Ninomiya, K.; Tanimoto, K.; Ishida, N.; Horii, D.; Sisido, M.; Itoh, T. J. Fluorine Chem. 2006, 127, 651-656. doi:10.1016/j.jluchem.2005.12.021

127.Collado, I.; Pedregal, C.; Bueno, A. B.; Marcos, A.; González, R.; Blanco-Urgoiti, J.; Pérez-Castells, J.; Schoepp, D. D.; Wright, R. A.; Johnson, B. G.; Kingston, A. E.; Moher, E. D.; Hoard, D. W.; Griffey, K. I.; Tizzano, J. P. J. Med. Chem. 2004, 47, 456-466. doi:10.1021/jm030967o

128. Buettelmann, B.; Kocer, B.; Kuhn, B.; Prunotto, M.; Richter, H.; Ritter, M.; Rudolph, M.; Satz, A. L. Triaza-spirodecanones as DDR1 inhibitors. WO Patent WO2017005583, Jan 12, 2017.

129.Lim, J.; Kelley, E. H.; Methot, J. L.; Zhou, H.; Petrocchi, A.; Mansoor, U. F.; Fischer, C.; O'Boyle, B. M.; Guerin, D. J.; Bienstock, C. E.; Boyce, C. W.; Daniels, M. H.; Falcone, D.; Ferguson, R. D.; Fevrier, S.; Huang, X.; Lipford, K. A.; Sloman, D. L.; Wilson, K.; Zhou, W.; Witter, D.; Maletic, M. M.; Siliphaivanh, P. Novel compounds that are ERK inhibitors. WO Pat. Appl. WO2013063214A1, May 2, 2013.

130. Marcin, L. R.; Higgins, M. A.; Bronson, J. J.; Zusi, F. C.; Macor, J. E.; Ding, M. Triazolopyrimidine ether derivatives and their use in neurological and psychiatric disorders. WO Pat Appl. WO2015042243A1, March 26, 2015.

131.Dilger, A. K.; Corte, J. R.; De Lucca, I.; Fang, T.; Yang, W.; Wang, Y.; Pabbisetty, K. B.; Ewing, W. R.; Zhu, Y.; Wexler, R. R.; Pinto, D. J. P.; Orwat, M. J.; Smith, L. M., II. Macrocyclic factor XIA inhibitors condensed with heterocycles. WO Pat. Appl. WO2015116882A1, Aug 6, 2015.

132.Liu, C.-H.; Wang, S.-A.; Ruszczycky, M. W.; Chen, H.; Li, K.; Murakami, K.; Liu, H.-w. Org. Lett. 2015, 17, 3342-3345. doi:10.1021/acs.orglett.5b01570

133. Franke, H.; Joppien, H.; Franke, H. Method of producing derivatives of difluorocyclopropane. USSR Patent 1500152, July 8, 1989.

\section{License and Terms}

This is an Open Access article under the terms of the Creative Commons Attribution License (https://creativecommons.org/licenses/by/4.0). Please note that the reuse, redistribution and reproduction in particular requires that the author(s) and source are credited and that individual graphics may be subject to special legal provisions.

The license is subject to the Beilstein Journal of Organic Chemistry terms and conditions: (https://www.beilstein-journals.org/bjoc/terms)

The definitive version of this article is the electronic one which can be found at: https://doi.org/10.3762/bjoc.17.25 